\title{
Comparison of the Effects of Early Pregnancy with Human Interferon, Alpha 2 (IFNA2), on Gene Expression in Bovine Endometrium ${ }^{1}$
}

\author{
Stefan Bauersachs, ${ }^{2,3,4}$ Susanne E. Ulbrich, ${ }^{5}$ Horst-Dieter Reichenbach, ${ }^{6}$ Myriam Reichenbach, ${ }^{3,7}$ Mathias \\ Büttner, ${ }^{8}$ Heinrich H.D. Meyer, ${ }^{5}$ Thomas E. Spencer, ${ }^{9}$ Megan Minten, ${ }^{9}$ Gerhard Sax, ${ }^{10}$ Gerhard Winter, ${ }^{10}$ \\ and Eckhard Wolf ${ }^{3,4}$ \\ ${ }^{3}$ Chair for Molecular Animal Breeding and Biotechnology, Gene Center, LMU Munich, Germany \\ ${ }^{4}$ Laboratory for Functional Genome Analysis (LAFUGA), Gene Center, LMU Munich, Germany \\ ${ }^{5}$ Physiology Weihenstephan, Technische Universitaet Muenchen, Freising, Germany \\ ${ }^{6}$ Institute for Animal Breeding, Bavarian State Research Center for Agriculture, Poing, Germany \\ ${ }^{7}$ Bavarian Research Center for Biology of Reproduction, Oberschleissheim, Germany \\ ${ }^{8}$ Bavarian Health and Food Safety Authority, Oberschleissheim, Germany \\ ${ }^{9}$ Department of Animal Sciences, Center for Reproductive Biology, Washington State University, Pullman, Washington \\ ${ }^{10}$ Chair for Pharmaceutical Technology and Biopharmaceutics, Department of Pharmacy, LMU Munich, Germany
}

\begin{abstract}
Interferon tau (IFNT), a type I IFN similar to alpha IFNs (IFNA), is the pregnancy recognition signal produced by the ruminant conceptus. To elucidate specific effects of bovine IFNT and of other conceptus-derived factors, endometrial gene expression changes during early pregnancy were compared to gene expression changes after intrauterine application of human IFNA2. In experiment 1, endometrial tissue samples were obtained on Day (D) 12, D15, and D18 postmating from nonpregnant or pregnant heifers. In experiment 2, heifers were treated from D14 to D16 of the estrous cycle with an intrauterine device releasing IFNA2 or, as controls, placebo lipid extrudates or PBS only. Endometrial biopsies were performed after flushing the uterus. All samples from both experiments were analyzed with an Affymetrix Bovine Genome Array. Experiment 1 revealed differential gene expression between pregnant and nonpregnant endometria on D15 and D18. In experiment 2, IFNA2 treatment resulted in differential gene expression in the bovine endometrium. Comparison of the data sets from both studies identified genes that were differentially expressed in response to IFNA2 but not in response to pregnancy on D15 or D18. In addition, genes were found that were differentially expressed during pregnancy but not after IFNA2 treatment. In experiment 3, spatiotemporal alterations in expression of selected genes were determined in uteri from nonpregnant and early pregnant heifers using in situ hybridization. The overall findings of this study suggest differential effects of bovine IFNT compared to human IFNA2 and that some
\end{abstract}

${ }^{1}$ Supported by the German Ministry for Education and Research (BMBF, FUGATO-plus, COMPENDIUM) and the German Research Foundation (DFG FOR478). The authors are part of the European Union COST action GEMINI.

${ }^{2}$ Correspondence: Stefan Bauersachs, Laboratory for Functional Genome Analysis (LAFUGA), Gene Center, LMU Munich, Feodor Lynen Str. 25, 81377 Munich, Germany. E-mail: bsachs@Imb.uni-muenchen.de

Received: 18 July 2011.

First decision: 14 August 2011.

Accepted: 10 October 2011

(C) 2012 by the Society for the Study of Reproduction, Inc.

elSSN: 1529-7268 http://www.biolreprod.org

ISSN: 0006-3363 pregnancy-specific changes in the endometrium are elicited by conceptus-derived factors other than IFNT.

endometrium, hormone action, pregnancy, reproductive immunology, uterus

\section{INTRODUCTION}

Interferons (IFNs) play a major role in establishment of pregnancy and conceptus (embryo and associated extraembryonic membranes) implantation in many, if not all, mammalian species [1-4]. Specific type I IFNs have evolved in several mammalian groups, such as delta IFNs in horses [5] and in pigs [3] and IFN tau (IFNT) in ruminants [6-9]. In some mammals (e.g., mice and pigs), IFN gamma, a type II IFN, has been implicated in regulation of conceptus implantation/attachment [10]. Type I and/or type II IFNs produced by trophoblast cells of the elongating conceptus induce the expression of a variety of IFN-stimulated genes (ISGs) in the endometrium during the peri-implantation period, which together with progesterone (P4)-induced genes are involved in many processes related to endometrial receptivity, such as attachment of the embryo to the endometrium surface, trophoblast outgrowth and proliferation, modulation of the maternal immune system, differentiation of uterine stromal cells, increased endometrial vascularization, transport of nutrients into the uterine lumen, and enhanced exchange of molecules between the conceptus and mother [4].

Produced by trophoblast cells, IFNT has a main function as the pregnancy recognition signal in ruminants that protects the functional corpus luteum (CL) [11]. IFNT is secreted in amounts coordinate with growth and development of the conceptus during elongation [8, 12], and it acts on the endometrial luminal epithelium (LE) to suppress transcription of the estrogen receptor alpha and oxytocin receptor genes in the endometrium, thereby preventing the uterus from producing luteolytic pulses of prostaglandin $\mathrm{F}_{2 \text { alpha }}$ (PGF2 $\alpha$ ) [13]. IFNT induces expression of a number of classical ISGs and increases expression of a number of P4-induced genes, thereby influencing a variety of processes in the endometrium related to endometrial receptivity, including modulation of the maternal immune system [14]. Very recently, IFNT was demonstrated to be released from the uterus into the circulation and to induce ISGs in the CL. Circulating IFNT is thought to initiate a peripheral antiviral response and to induce luteal 
resistance to $\mathrm{PGF} \alpha$ via endocrine mechanisms contributing to longer-term survival of the CL and maintenance of pregnancy [15].

Similar to other classical type I IFNs, IFNT acts via the type I IFN alpha receptor dimer (IFNAR1/2) [16]. Whereas some authors showed that bovine IFNT and bovine IFN alpha (IFNA) bind to the same receptor with similar dissociation constants [17], others found a lower binding affinity of IFNT compared to IFNA [18]. With regard to estrous cycle extension, similar effects were shown for IFNA and IFNT in sheep when equivalent bioactivity doses (antiviral activity) were given [19]. Thus, the uniqueness of IFNT is thought to be its developmentally related expression regulation rather than any special biopotency, although IFNT appears to have less cytotoxic effects compared to IFNA based on in vitro and in vivo studies $[18,20]$. Similar to sheep, infusion of recombinant bovine IFNA into the uterus delayed luteolysis in cyclic cows [21]. Various studies showed binding of human IFNA to ovine IFNAR [22, 23], and similar effects of human IFNA and ovine IFNT on release of prostaglandin E and PGF $2 \alpha$ from cultured ovine endometrial cells have been found [24]. A number of microarray studies have been performed to characterize the highly complex responses of the endometrium at the level of gene expression during early pregnancy or after administration of IFNT in cattle [25-30] and in sheep [31-33]. These studies revealed large numbers of differentially expressed genes (DEGs) in the endometrium in response to P4, IFNT, and the conceptus, suggesting that a number of biological processes and pathways play a role in the establishment and maintenance of pregnancy in ruminants.

The present microarray study was conducted to analyze differential gene expression in bovine intercaruncular endometrium during the preimplantation phase and to compare the results obtained with the effects of a "standard" type I IFN to identify specific effects of IFNT and/or additional conceptusderived factors. To accomplish this, gene expression in bovine endometrium was analyzed on Day (D) 12, D15, and D18 of pregnancy and corresponding nonpregnant control stages, where D12 was chosen as the time immediately before conceptus elongation, D15 as a time point during conceptus elongation and increasing secretion of IFNT, and D18 as the time before conceptus implantation. In the second experiment, endometrial gene expression was analyzed after administration of human IFNA2 or controls from D14 to D16 of the estrous cycle, the period of maternal recognition of pregnancy, using slow-releasing lipid extrudates. The comparison of the results of both experiments identified genes that differ in their response to pregnancy and their response to IFNA2, suggesting specific effects of IFNT and/or modulatory effects of other conceptus-derived factors.

\section{MATERIAL AND METHODS}

\section{Preparation of Recombinant Human IFNA2 Containing Lipid Extrudates}

Triglyceride-based lipid twin-screw extrudates were prepared from powder mixtures of two lipids (D118, glycerol tristearate; H12, mixed-acid triglyceride comprising lauric, myristic, and palmitic acids; Sasol GmbH, Witten, Germany), a pore-forming excipient (hydroxypropyl- $\beta$-cyclodextrin; Merck, Darmstadt, Germany), and recombinant human IFNA2 lyophilizate (1:3 with hydroxypropyl- $\beta$-cylcodextrin; Roferon; Roche Diagnostics, Penzberg, Germany) as described by Schulze and Winter [34]. In brief, H12, D118, mannitol $(30 \%)$, and IFNA2 lyophilizate (2\%) were admixed in an agate mortar, fed into the barrel of a Minilab Micro Rheology Compounder (Thermo Haake GmbH), and extruded with a closed-bypass channel through the extruder outlet die (1.9 $\mathrm{mm}, 40 \mathrm{rpm}, 41^{\circ} \mathrm{C}$; twin screw extruder, MiniLab Micro Rheology Compounder, Thermo Haake GmbH, Karlsruhe, Germany). Rod-shaped extrudates were cut at a length of approximately $2.0 \mathrm{~cm}$ and weighed on an analytical balance.

Extrudates $(\mathrm{n}=6)$ were placed in $1.9 \mathrm{ml}$ of PBS containing $0.05 \%$ sodium azide at $\mathrm{pH} 6.6$ to mimic the $\mathrm{pH}$ in the uteri of cows [35]. At predetermined points, samples were drawn by complete exchange of the incubation medium and subsequently quantified UV-spectrophotometrically (UV 1000, Thermo Electron Corporation, Dreieich, Germany; $215 \mathrm{~nm}$ ) after separation by sizeexclusion high-performance liquid chromatography (TSKgel G3000SWXL column; Tosoh Biosep, Stuttgart, Germany; flow rate: $0.6 \mathrm{ml} / \mathrm{min}$, Dionex Ultimate 3000, Dionex GmbH, Idstein, Germany) as described by Mohl and Winter [36].

\section{IFN Bioassay}

The antiviral activity of recombinant human IFNA2 and the antiviral activity present in uterine flushings were quantified by means of a bioassay based on the inhibition of the cytopathic effect of vesicular stomatitis virus (Indiana strain) on Madin-Darby bovine kidney (MDBK; American Type Culture Collection CRL-6071) cells [37]. The National Institutes of Health (NIH) recombinant human IFNA2 reference preparation (Gxa01-901-535) was included in each assay. One unit of IFN per milliliter corresponds to the quantity necessary for a cytopathic effect of $50 \%$ (i.e., $50 \%$ inhibition of cell lysis). Recombinant human IFNA2 $(1.56 \mathrm{mg} / \mathrm{ml})$ was diluted $10^{7}$-fold for the starting dilution. Uterine flushings were not diluted for the starting dilution of the assay. Twofold dilutions were performed, and the dilution with a $50 \%$ cytopathic effect corresponded to $1 \mathrm{U}$ of antiviral activity. The antiviral activity was shown to be IFN, because the effects of uterine flushings and appropriate control IFN preparations were blocked by specific anti-IFN sera.

\section{Treatment of Heifers and Collection of Endometrial Tissue Samples}

Heifers for experiments 1 and 2 were housed in the facilities of the Bavarian State Research Center for Agriculture. Treatments of heifers were approved and performed with permission of the local authorities (District Government of Upper Bavaria, Germany). Experiments with heifers were performed in accordance with the International Guiding Principles for Biomedical Research Involving Animals as proposed by the Society for the Study of Reproduction, with the European Convention on Animal Experimentation, and with the German Animal Welfare Act.

Experiment 1: Early pregnancy. The estrous cycles of German Simmental heifers between 16 and 26 mo old were synchronized by an intramuscular injection of a single dose of $500 \mu \mathrm{g}$ of cloprostenol (PGF2 $\alpha$; Estrumate; Intervet) at diestrus. Presence of a functional CL was checked by transrectal palpation. Sexual behavior of heifers (i.e., toleration, sweating, and vaginal mucus) was observed to determine standing heat, which occurred approximately $60 \mathrm{~h}$ after cloprostenol injection. In addition, ultrasound-guided follicle monitoring was performed to check follicle development. Blood samples were taken 2 days before estrus (Day -2), at estrus (D0), and just before slaughter to determine P4 concentrations. Heifers without signs of estrus (standing heat) were excluded. Heifers assigned to the insemination group were inseminated on D1 with cryopreserved sperm (ejaculate + diluter, 1:10) of the same bull and slaughtered at D12, D15, or D18. Cyclic control heifers received sperm-free supernatant of cryopreserved sperm. Five milliliter of sperm were transferred to centrifugation vials and centrifuged at $3500 \times g$ at room temperature for 10 min. Supernatant was transferred to fresh vials and centrifuged again. Absence of spermatocytes was controlled under a microscope. Sperm supernatant was then transferred to $0.25 \mathrm{ml}$ semen straws and stored at $-4^{\circ} \mathrm{C}$ until insemination a few days later. After slaughter at the corresponding days of the estrous cycle, collected uteri were trimmed free from surrounding tissue, and uterine horns were opened longitudinally. In heifers slaughtered on D12, the uteri were flushed with PBS before opening to determine the presence of a blastocyst. The D12 control heifers were also flushed. For D15 and D18, pregnancy was confirmed by presence of a conceptus that was carefully removed before collecting endometrial tissue samples. Endometrial tissue samples were collected from the uterine horns ipsilateral to the functional CL (specifically, from the cranial uterine part for D12 heifers, from the middle part for D15 heifers, and from the caudal part for D18 heifers). Samples were carefully cut from the lamina propria of the intercaruncular endometrium with a scalpel and immediately transferred into vials containing $4 \mathrm{ml}$ of RNAlater (Ambion) and then incubated overnight at $4^{\circ} \mathrm{C}$. Subsequently, samples were removed from RNAlater and stored at $-80^{\circ} \mathrm{C}$ until further processing. For D12, five pregnant heifers and five controls and, for D15 and D18, four pregnant heifers and four controls, respectively, were selected for microarray and quantitative real-time RT-PCR (qPCR analyses) based on appropriate P4 concentrations (Day -2, 
D0, and day of slaughter), state of the ovaries at slaughter, and the presence of a conceptus in the pregnancy groups.

Experiment 2: Treatment with human IFNA2. The estrous cycles of 15 German Simmental heifers between 23 and 25 mo old were synchronized as described for experiment 1. Blood samples were taken at the day of cloprostenol injection (Day -2), at estrus (D0), at D7 and D14 of the estrous cycle, and daily from D16 to D26 to determine serum P4 concentrations. Presence of a functional CL was checked on D7 and D14 by transrectal ultrasonography. Based on P4 concentrations on D7 and results of ultrasonography, 12 animals were selected and randomly assigned to one of the following three treatment groups. In the IFNA2 treatment group (IFNA; $\mathrm{n}=$ 4 heifers), a rod-shaped human IFNA2-releasing lipid extrudate was loaded in PBS into a $0.5-\mathrm{ml}$ artificial insemination straw and nonsurgically (via the cervix) transferred into the uterine horn ipsilateral to the functional CL on D14 using an insemination pipette. Two control groups were used: The placebo group (PLAC; $n=4$ ) received only the rod-shaped lipid extrudate, whereas the other control group $(\mathrm{CONT} ; \mathrm{n}=4)$ received PBS only. Based on in vitro release experiments, IFNA2 concentration and lipid formulation were adjusted to release $8-9 \times 10^{7}$ IU of IFNA2 over a period of 2 days. The proposed release of IFNA2 over the 2-day period was based on data from previous studies with sheep in which intrauterine applications of IFNT or IFNA have been performed $[19,38,39]$. On D16 of the estrous cycle, uteri were nonsurgically flushed with $10 \mathrm{ml}$ of PBS using an embryo-flushing catheter (type Dissi, CH12; Minitüb). Flushing medium was collected in 50-ml Falcon tubes (Nunc) and frozen for estimation of antiviral activity. After flushing, six ( \pm one) uterine biopsy samples were collected per heifer from the ipsilateral horn by the use of an uterine biopsy forceps (type 8151.07; length, $450 \mathrm{~mm}$; diameter, $2.2 \mathrm{~mm}$; Richard Wolf), which was nonsurgically inserted into the uterine horn through a self-shortened transcervical plastic cannula (type bovivet; Henry Schein) under rectal palpation control. The weight of one biopsy sample was approximately $5 \mathrm{mg}$. Biopsy samples were pooled for each heifer, transferred to $1 \mathrm{ml}$ of RNAlater, and incubated overnight at $4^{\circ} \mathrm{C}$. Subsequently, samples were removed from RNAlater and stored at $-80^{\circ} \mathrm{C}$ until further processing.

Experiment 3: In situ localization of mRNAs in the bovine uterus. As described previously [40], cross-bred nulliparous beef heifers were artificially inseminated with semen from a single bull after a timed, artificial insemination synchronization protocol [41] and then slaughtered on D10, D13, D16, or D19 after mating. The uterus was flushed with $20 \mathrm{ml}$ of sterile $10 \mathrm{mM}$ Tris buffer $(\mathrm{pH}$ 7.2). Heifers were classified as pregnant if the uterine flush contained a blastocyst/conceptus of the correct morphology and size or as nonpregnant if the uterine flush did not contain a blastocyst/conceptus. Uterine tissues were collected from nonpregnant heifers on D10, D13, D16, and D19 ( $\mathrm{n}=5$ per day) and from pregnant heifers on D13, D16, and D19 ( $\mathrm{n}=6$ per day). Portions of the uterus ipsilateral to the $\mathrm{CL}$ were fixed in $4 \%$ paraformaldehyde in $\mathrm{PBS}(\mathrm{pH}$ 7.2) overnight and then embedded in paraffin for immunohistomolecular analyses.

\section{Affymetrix GeneChip Hybridization and Data Analysis}

Total RNA was isolated from endometrial tissue samples using TRIzol (Invitrogen) according to the manufacturer's instructions. The quantity and quality of total RNA was determined using spectrophotometry, agarose gel electrophoresis, and a Bioanalyzer 2100 (Agilent Technologies). RNA integrity numbers were 7.6-8.4 for samples from the IFNA experiment, 8.5-9.5 for samples from D12, 8.3-9.2 for samples from D15, and 8.2-9.0 for samples from D18. Preparation of hybridization probes for Affymetrix GeneChip Bovine Genome Arrays (Affymetrix) was performed using $10 \mu \mathrm{g}$ of total RNA and the One-Cycle Target Labeling and Control Reagent package (Affymetrix). For the hybridization, wash, and staining process, the GeneChip Hybridization, Wash, and Stain Kit (Affymetrix) and a Fluidic Station 450 (Affymetrix) were used. All steps were done according to the manufacturer's protocol. The processed arrays were scanned with a GeneChip Scanner 3000 7G with AutoLoader (Affymetrix).

Affymetrix CEL files were processed with the robust multiarray average method [42]. Quality control was done using a variety of tools, such as pseudoimages (BioC package AffyPLM), RNA degradation plots (BioC package Affy), different box plots, distance matrices, and heatmaps. Probe sets were filtered based on expression calls before significance analysis. Only probe sets were used with present calls in at least three of four (D15 and D18) or four of five (D12) samples in at least one of the respective experimental groups. Significance analysis was performed with the function decideTests of the BioC package Limma [43], and multiple testing correction was done using the parameter fdr to calculate adjusted $P$ values. Probe set annotation of the bovine Affymetrix Genome Array was improved based on mapping to the bovine genome, and the putative human orthologous genes were assigned. If a transcript was represented on the arrays by more than one probe set, the mean values for fold-change and adjusted $P$ values were calculated.
For Gene Set Enrichment Analysis (GSEA) [44], genes were preranked based on expression fold-change (pregnant vs. control) and the adjusted $P$ value $\left(\log _{2}(\right.$ fold-change +2$) \cdot-\log _{10}(P$ value $)$, resulting in a ranked gene list containing the most significantly upregulated genes at the top of the list and the most significantly downregulated genes at the bottom. This preranked gene list was compared with GSEA gene sets c2.all.v3.symbols.gmt (curated) and other published gene sets. Classification of DEGs and identification of quantitatively enriched functional categories were done using different tools of the Database for Annotation, Visualization, and Integrated Discovery (DAVID) [45]. Identification of biological keywords cocited with DEGs in PubMed abstracts was performed with CoPub [46]. Analysis of functional databases was based on the Entrez Gene ID of the putative human orthologous genes.

The data discussed in the present publication have been deposited in the National Center for Biotechnology Information Gene Expression Omnibus (GEO; http://www.ncbi.nlm.nih.gov/geo/) and are accessible through GEO Series accession no. GSE30694.

\section{Quantitative Real-Time RT-PCR}

The same RNA samples used for microarray analysis were used for qPCR. First-strand cDNA was synthesized starting from $1 \mu \mathrm{g}$ of total RNA with the Sprint RT Complete-Double PrePrimed Kit (Takara Bio Europe/Clontech). Two-step qPCR experiments were performed as described previously [47] in accordance with the Minimum Information for Publication of Quantitative Real-Time PCR Experiments (MIQE) guidelines [48] and using a LightCycler DNA Master SYBR Green I protocol (Roche). The cycle threshold $(\mathrm{Ct})$ required for achieving a definite SYBR Green fluorescence signal was calculated by the second derivative maximum method (LightCycler software version 3.5.28). The $\mathrm{Ct}$ is correlated inversely with the logarithm of the initial template concentration. The $\mathrm{Ct}$ values determined for the target genes were normalized against the geometric mean of the reference genes $\mathrm{H} 3$ histone, family $3 \mathrm{~A}(H 3 F 3 A)$ and polyubiquitin (LOC281370) $(\triangle \mathrm{CT})$ [49]. Reference genes were chosen from three potential reference genes (H3F3A, LOC281370, and $G A P D H)$ based on GeNorm analysis. Finally, the relative expression differences between the corresponding experimental groups were calculated $(\Delta \Delta \mathrm{CT})$. All amplified PCR fragments were sequenced to verify the concordance with the corresponding target sequence. The sequences of the PCR primers, size of PCR products, annealing temperature, melting point, and fluorescence acquisition temperature are listed in Supplemental Table S1 (all Supplemental Data are available online at www.biolreprod.org).

\section{In Situ Hybridization}

Cell-specific expression of mRNAs in cross-sections of bovine uteri ( $n=5$ per day and status) from experiment 3 was determined using radioactive in situ hybridization analysis conducted using methods described previously [50]. Partial cDNAs for bovine endometrial DKK1, FABP3, IDO1, IFI27, and $J H D M 1 D$ mRNAs were cloned by RT-PCR using specific primers and then sequenced to confirm identity (data not shown). All slides for each respective gene were exposed to photographic emulsion for the same period of time. Images of representative fields were recorded under bright-field or dark-field illumination using a Nikon Eclipse 1000 photomicroscope fitted with a Nikon DXM1200 digital camera.

\section{RESULTS}

Antiviral Activity of Human IFNA2 on MDBK Cells, In Vitro IFNA2 Release Data, and Antiviral Activity in Uterine Flushings

The antiviral activity of human IFNA2 was evaluated on MDBK cells to estimate the amount of IFNA2 protein for the slow-releasing lipid extrudates. This assay revealed that the recombinant human IFNA2 contained $410 \mathrm{IU} / \mathrm{ng}$ protein. Next, rod-shaped IFNA2-releasing lipid extrudates were produced, and IFNA2 release was tested in vitro to find the appropriate lipid formulation for a cumulative release of approximately $9 \times$ $10^{7} \mathrm{IU}$ over 2 days (Table 1 and Supplemental Fig. S1). To examine the release in vivo, antiviral activity in uterine flushings collected on D16 after transfer of lipid extrudates on D14 was measured. Antiviral activity was not detectable in PLAC, but $0-160$ IU were estimated in CONT and $0.82-6.5 \times$ $10^{6} \mathrm{IU}$ per flushing in IFNA. 
TABLE 1. In vitro release of human IFNA2 from lipid extrudates.

\begin{tabular}{lccccc}
\hline Time $(\mathrm{h})$ & 13.9 & 25.0 & 46.1 & 72.0 & 94.1 \\
\hline Mean cumulative IFNA2 release $(\mathrm{mg})$ & 0.148 & 0.176 & 0.212 & 0.229 & 0.234 \\
Standard deviation & 0.018 & 0.010 & 0.0136 & 0.016 & 0.017 \\
Mean cumulative IFNA2 release $\left(10^{6} \mathrm{IU}\right)$ & 60.6 & 72.2 & 86.9 & 9.241 \\
Standard deviation & 7.4 & 4.3 & 5.6 & 6.7 & 9.018 \\
\hline
\end{tabular}

\section{Serum P4 Concentrations}

For the D12 nonpregnant controls, serum P4 concentrations were from 2.7 to $6.0 \mathrm{ng} / \mathrm{ml}$ on the day of PGF $2 \alpha$ injection, from less than 0.2 to $0.6 \mathrm{ng} / \mathrm{ml}$ on D0, and from 7.2 to $9.9 \mathrm{ng} /$ $\mathrm{ml}$ on D12 of the estrous cycle. The D12 pregnant heifers had serum P4 concentrations ranging from 3.6 to $4.8 \mathrm{ng} / \mathrm{ml}$ on the day of PGF $2 \alpha$ injection, less than $0.2 \mathrm{ng} / \mathrm{ml}$ on D0, and from 5.2 to $12.5 \mathrm{ng} / \mathrm{ml}$ on D12 after estrus. The D15 nonpregnant controls showed $\mathrm{P} 4$ concentrations ranging from 1.3 to $3.7 \mathrm{ng} /$ $\mathrm{ml}$ on the day of PGF2 $\alpha$ injection, from less than 0.2 to $0.8 \mathrm{ng} /$ $\mathrm{ml}$ on $\mathrm{D} 0$, and from 1.9 to $8.3 \mathrm{ng} / \mathrm{ml}$ on D15 of the estrous cycle. The P4 concentrations of D15 pregnant heifers were from 1.2 to $3.7 \mathrm{ng} / \mathrm{ml}$ on the day of PGF2 $\alpha$ injection, from less than 0.2 to $0.4 \mathrm{ng} / \mathrm{ml}$ on D0, and from 5.2 to $10.4 \mathrm{ng} / \mathrm{ml}$ on D15 after estrus. On D18, P4 concentrations were from 4.1 to $5.9 \mathrm{ng} / \mathrm{ml}$ on the day of PGF2 $\alpha$ injection, less than $0.2 \mathrm{ng} / \mathrm{ml}$ on D0, and from 3.5 to $7.6 \mathrm{ng} / \mathrm{ml}$ on D18 of the estrous cycle for the control heifers. For the D18 pregnant heifers, P4 concentrations were from 5.1 to $6.7 \mathrm{ng} / \mathrm{ml}$ on the day of PGF2 $\alpha$ injection, from less than 0.2 to $0.3 \mathrm{ng} / \mathrm{ml}$ on D0, and from 6.3 to $17.9 \mathrm{ng} / \mathrm{ml}$ on $\mathrm{D} 18$ after estrus. (For individual P4 concentrations, see Supplemental Table S2a.)

For the heifers used in experiment 2 (IFNA study), serum P4 concentrations were measured at the time of cloprostenol injection (PGF2 $\alpha$ ), D0 (estrus), D7, D14, and from D16 to D26 (Supplemental Table S2b). All heifers had basal concentrations of P4 at D0 $(<0.2 \mathrm{ng} / \mathrm{ml})$. However, P4 concentrations were from 1.2 to $5.0 \mathrm{ng} / \mathrm{ml}$ at D7, from 5.2 to $8.6 \mathrm{ng} / \mathrm{ml}$ at D14, and from 3.1 to $7.9 \mathrm{ng} / \mathrm{ml}$ at D16. Some heifers showed basal P4 concentrations as early as the period from D11 to D18 (one heifer in each group). All heifers had basal P4 concentrations on D23. No significant difference was found between the treatment groups at any time point. Signs of estrus were observed between D23 and D26 for all heifers.

\section{Differential Gene Expression at D12, D15, and D18 of Pregnancy}

Messenger RNA abundance in pregnant and cyclic endometrial tissue samples was analyzed at three different times of pregnancy: at D12, when the hatched blastocyst has a diameter of approximately $1 \mathrm{~mm}$; at D15, when the elongated conceptus has a length of between 3 and $5 \mathrm{~cm}$; and at D18, when the conceptus trophoblast is beginning to attach to the endometrial LE [51, 52]. Antiviral activity in bovine uterine flushings at D12 was not detectable, whereas considerable amounts were measured at D15 and more than 100-fold higher amounts at D18 [53].

At D12 of pregnancy, no DEGs were found (adjusted $P$ values $>0.1385$ ). Analysis of microarray data for D15 samples revealed that one sample of the pregnant group (15P) clustered to the cyclic group (15C) and showed intermediate expression levels for ISGs. In addition, one cRNA sample of $15 \mathrm{C}$ was identified as an outlier for technical and, probably, biological reasons (obviously lower serum P4 concentration on D15 compared to the other D15 cyclic controls). These two samples were omitted for further data analysis, which was done with the remaining six samples ( $n=3$ per group). Statistical analysis resulted in 309 DEGs at D15 of pregnancy (adjusted $P$ value $<$ 0.05 , fold-change $>1.5$ ), of which 245 had higher levels and 64 had lower levels in pregnant endometrium (Supplemental Table S3). At D18 of pregnancy, 941 differentially expressed transcripts were identified (adjusted $P$ value $<0.05$, foldchange $>1.5$ ), of which 602 had higher levels and 339 had lower levels in the D18 pregnant group (18P) (Supplemental Table S4). A comparison of the DEGs found at D15 and D18 showed that 212 of the 309 DEGs at D15 were also differentially expressed (false-discovery rate $[\mathrm{FDR}]=1 \%$, fold-change $>1.5$ ) at D18. For the majority of these genes, the fold-change of mRNA expression was higher at D18 (Supplemental Fig. S2).

TABLE 2. Selected results of Gene Set Enrichment Analysis of the Day 15 pregnant vs. control data set.

\begin{tabular}{|c|c|c|c|c|c|c|c|}
\hline Gene set & $\operatorname{Size}^{\mathrm{a}}$ & $\mathrm{NES}^{\mathrm{b}}$ & $\begin{array}{c}\text { FDR } \\
\text { q value }\end{array}$ & $\begin{array}{l}\text { FWER } \\
P \text { value }^{\mathrm{d}}\end{array}$ & $\begin{array}{l}\text { Rank at } \\
\max \end{array}$ & $\begin{array}{l}\text { No. genes matching top } \\
300 \text { or bottom }\left(^{*}\right) 100^{\mathrm{e}}\end{array}$ & $\begin{array}{l}\text { Percent } \\
(\%)^{\mathrm{f}}\end{array}$ \\
\hline D16 of pregnancy upregulated Forde et al. [28] & 285 & 3.65 & $<0.001$ & $<0.001$ & 779 & 150 & 52.6 \\
\hline D17 of pregnancy upregulated Walker et al. [30] & 319 & 3.60 & $<0.001$ & $<0.001$ & 1111 & 142 & 44.5 \\
\hline D18 of pregnancy upregulated Klein et al. [25] & 66 & 3.16 & $<0.001$ & $<0.001$ & 196 & 43 & 65.2 \\
\hline D18 of pregnancy upregulated (this study) & 524 & 3.81 & $<0.001$ & $<0.001$ & 958 & 214 & 40.8 \\
\hline D20 of pregnancy upregulated Mansouri-Attia et al. [29] & 36 & 2.51 & $<0.001$ & $<0.001$ & 163 & 13 & 36.1 \\
\hline Browne IFN-responsive genes [90] & 51 & 2.96 & $<0.001$ & $<0.001$ & 284 & 35 & 68.6 \\
\hline D16 of pregnancy downregulated Forde et al. [28] & 136 & -2.52 & $<0.001$ & $<0.001$ & 3277 & $7^{*}$ & 5.1 \\
\hline D17 of pregnancy downregulated Walker et al. [30] & 207 & -1.96 & 0.004 & 0.046 & 2899 & $3 *$ & 1.4 \\
\hline D18 of pregnancy downregulated (this study) & 324 & -3.04 & $<0.001$ & $<0.001$ & 2406 & $31^{*}$ & 9.6 \\
\hline
\end{tabular}

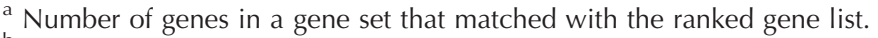

b NES, normalized enrichment score.

${ }^{\mathrm{c}} \mathrm{FDR}$, false discovery rate.

${ }^{\mathrm{d}}$ FWER, family-wise error rate.

e Number of genes matching with the top 300 or the bottom 100 (designated by italics and an asterisk) of pre-ranked gene list.

${ }^{f}$ Percentage in relation to the size of the gene set. 
TABLE 3. Selected results of Gene Set Enrichment Analysis of the Day 18 pregnant vs. control data set.

\begin{tabular}{|c|c|c|c|c|c|c|c|}
\hline Gene set & $\operatorname{Size}^{\mathrm{a}}$ & $\mathrm{NES}^{\mathrm{b}}$ & $\begin{array}{c}\text { FDR } \\
\text { q value }\end{array}$ & $\begin{array}{l}\text { FWER }^{\mathrm{d}} \\
P \text { value }^{\mathrm{d}}\end{array}$ & $\begin{array}{l}\text { Rank at } \\
\max \end{array}$ & $\begin{array}{l}\text { No. genes matching top } \\
300 \text { or bottom }\left(^{*}\right) 100^{\mathrm{e}}\end{array}$ & $\begin{array}{l}\text { Percent } \\
(\%)^{\mathrm{f}}\end{array}$ \\
\hline D15 of pregnancy upregulated (this study) & 246 & 3.63 & $<0.001$ & $<0.001$ & 653 & 189 & 76.8 \\
\hline D16 of pregnancy upregulated Forde et al. [28] & 294 & 3.63 & $<0.001$ & $<0.001$ & 928 & 204 & 69.4 \\
\hline D17 of pregnancy upregulated Walker et al. [30] & 355 & 3.62 & $<0.001$ & $<0.001$ & 785 & 229 & 64.5 \\
\hline D18 of pregnancy upregulated Klein et al. [25] & 69 & 3.10 & $<0.001$ & $<0.001$ & 296 & 51 & 73.9 \\
\hline D20 of pregnancy upregulated Mansouri-Attia et al. [29] & 36 & 2.40 & $<0.001$ & $<0.001$ & 511 & 16 & 44.4 \\
\hline Browne IFN-responsive genes [90] & 52 & 2.85 & $<0.001$ & $<0.001$ & 794 & 42 & 80.8 \\
\hline D15 of pregnancy downregulated (this study) & 59 & -2.72 & $<0.001$ & $<0.001$ & 1571 & $24^{*}$ & 40.7 \\
\hline D16 of pregnancy downregulated Forde et al. [28] & 140 & -2.86 & $<0.001$ & $<0.001$ & 2176 & $37^{*}$ & 26.4 \\
\hline D17 of pregnancy downregulated Walker et al. [30] & 235 & -2.56 & $<0.001$ & $<0.001$ & 2207 & $38^{*}$ & 16.2 \\
\hline D20 of pregnancy downregulated Mansouri-Attia et al. [29] & 42 & -0.84 & 0.902 & 1.000 & 1380 & $2 *$ & 4.8 \\
\hline Reactome peptide chain elongation & 80 & -2.31 & $<0.001$ & 0.001 & 3696 & $6^{*}$ & 7.5 \\
\hline
\end{tabular}

a Number of genes in a gene set that matched with the ranked gene list.

b NES, normalized enrichment score.

${ }^{\mathrm{C}} \mathrm{FDR}$, false discovery rate.

d FWER, family-wise error rate.

e Number of genes matching with the top 800 or the bottom 400 (designated by italics and an asterisk) of pre-ranked gene list.

${ }^{f}$ Percentage in relation to the size of the gene set.

Next, GSEA [44] was performed to compare the obtained data sets for D15 and D18 of pregnancy with results of similar studies in bovine endometrium from D16, D17, D18, and D20 of pregnancy. GSEA was also used to compare the D15 and D18 data sets to gene sets of the GSEA Molecular Signature Database. For the D15 data set, a substantial enrichment toward the upregulated genes was found for genes that have been identified as upregulated in bovine intercaruncular endometrium on D16 [28], on D17 [30], and on D18 (genes from Klein et al. [25] and from the present study) of pregnancy (Table 2 and Supplemental Fig. S3). A moderate enrichment was also found for genes identified as upregulated on D20 of pregnancy by Mansouri-Attia et al. [29]. Furthermore, strong enrichment toward the upregulated genes was found for many gene sets related to IFN-responsive genes. In contrast, moderate enrichment toward the downregulated genes was only found for genes downregulated on D18 identified in the present study.

For the D18 data set, results were similar to those obtained for the D15 data set for genes found as upregulated on D16, D17, D18, and D20 of pregnancy and for IFN-responsive genes (Table 3 and Supplemental Fig. S4). Strong enrichment was also found for the genes upregulated on D15 of pregnancy. Moderate enrichment toward the D18 downregulated genes was observed for genes that have been found as downregulated on D16 and D17 of pregnancy and for the genes downregulated on D15 identified in the present study. No significant enrichment was obtained for the genes identified as downregulated on D20 of pregnancy by Mansouri-Attia et al. [29] and other gene sets of the GSEA database except for a few gene sets related to ribosomal proteins.

The DAVID functional annotation clustering was performed to characterize the known or inferred functions of the obtained DEGs for D15 and D18 of pregnancy. Both the D15 and the D18 upregulated genes revealed almost exclusively overrepresented functional terms related to typical responses to type I IFNs, such as inflammatory response, defense response, ubiquitin-like modifier conjugation pathway, proteolysis (complement components, ubiquitin pathway, proteasome subunits), and cell death. The typical IFN response categories contained more members on D18 compared to D15 of pregnancy (Supplemental Table S5). For some categories, members of gene families came up that were not differential on D15-for example, members of the chemokine (C-C motif) receptor family and of the suppressor of cytokine signaling family. The analysis of the D15 downregulated genes revealed only few significantly enriched annotation clusters that contained genes with potential binding sites for a number of transcription factors-for example, for nuclear factor of kappa light polypeptide gene enhancer in B-cells 1 (NFKB1) and for H6 family homeobox 1 (HMX1). The annotation cluster with the highest enrichment score for the analysis of the D18 downregulated genes also contained genes with potential binding sites for transcription factors-for example, forkhead box C1 (FOXC1) and forkhead box L1 (FOXL1) (Supplemental Table S6). Furthermore, functional terms related to secreted proteins and proteins of the extracellular matrix (ECM), cell adhesion, regulation of transcription, neuronal differentiation, and homeobox proteins were found as overrepresented for the genes downregulated on D18 of pregnancy (Supplemental Table S6).

\section{Effects of Treatment with Human IFNA2 on Endometrial Gene Expression}

The analysis of microarray expression data revealed that one PLAC sample showed elevated expression levels for typical type I IFN-induced genes (e.g. ISG15, MX1, MX2, and IFIT2). This elevated expression was confirmed by qPCR (data not shown). This animal had no obvious fever, mastitis, or other infections with clinical symptoms. However, a subclinical infection or an individual reaction to the transfer of the placebo lipid extrudate cannot be excluded. Furthermore, one cRNA sample of the IFNA treatment group turned out to be a technical outlier. Therefore, Limma analysis was performed with three biological replicates per group. Statistical analysis resulted in 236 differentially expressed probe sets for IFNA versus PLAC (221 with higher and 15 with lower levels in IFNA) and 212 differentially probe sets for IFNA versus CONT (173 with higher and 39 with lower levels in IFNA) at an FDR of $5 \%$ and a fold-change of 1.5 or greater. No significant differences were found between PLAC and CONT (adjusted $P$ value $>0.6$ ). The overlap between the three contrasts is shown in the Venn diagram in Figure 1A. A consistent overlap was found between IFNA versus PLAC and between IFNA versus CONT for the probes with higher levels in the IFNA group. Of note, only six probes were significantly reduced in both IFNA versus PLAC and IFNA versus CONT. Expression patterns based on the probes showing differential expression were further investigated by a cluster analysis of the individual samples. The results of this analysis are shown in 
A

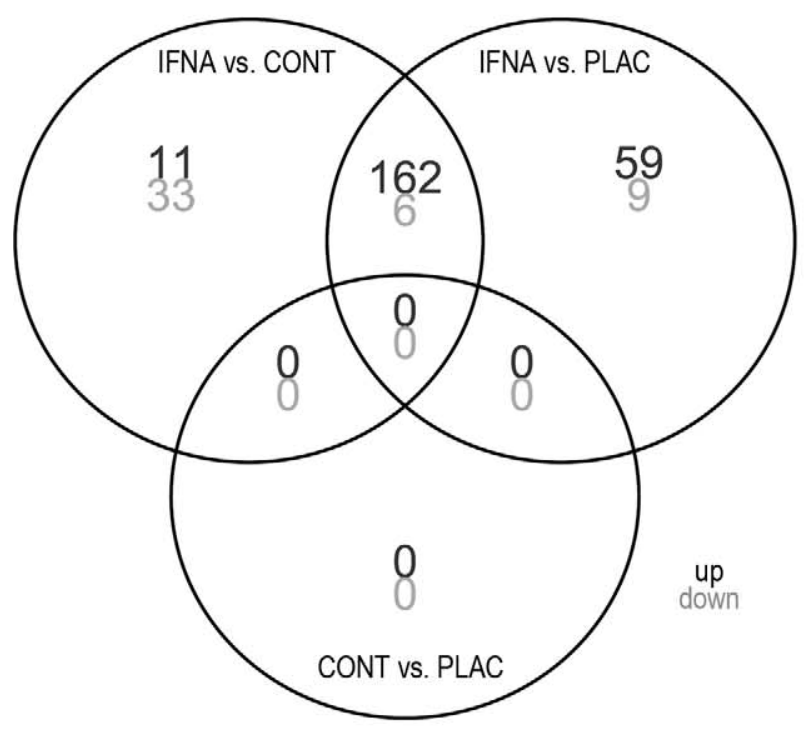

$-2$

0

B

C IFNA vs. PLAC IFNA vs. CONT 18P vs. $18 \mathrm{C}$ 15P vs. $15 \mathrm{C}$

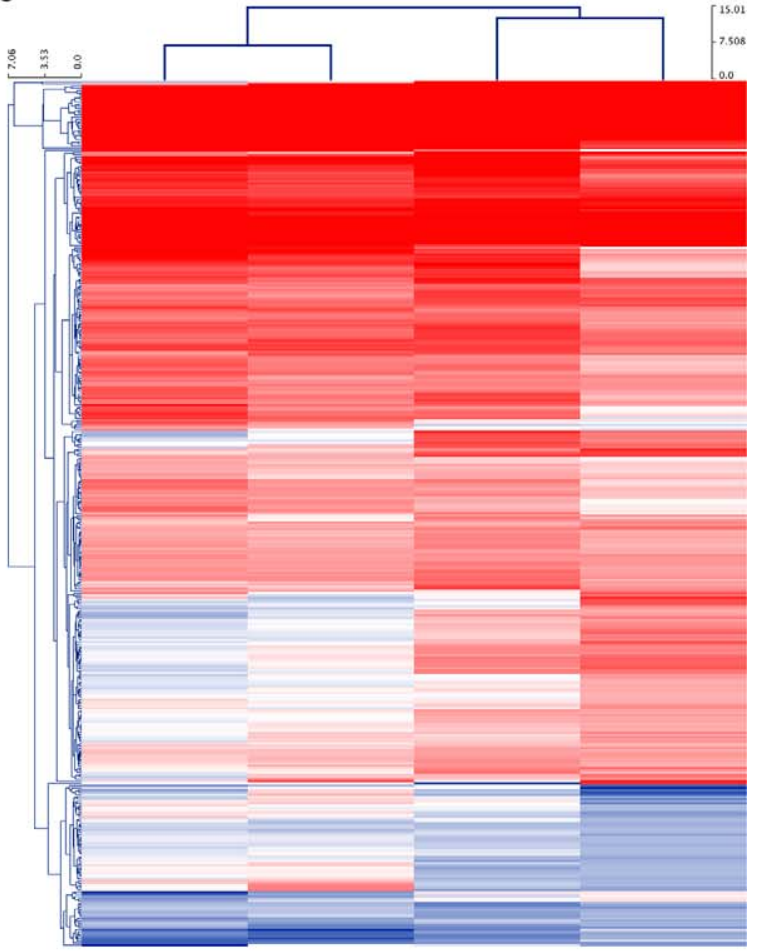

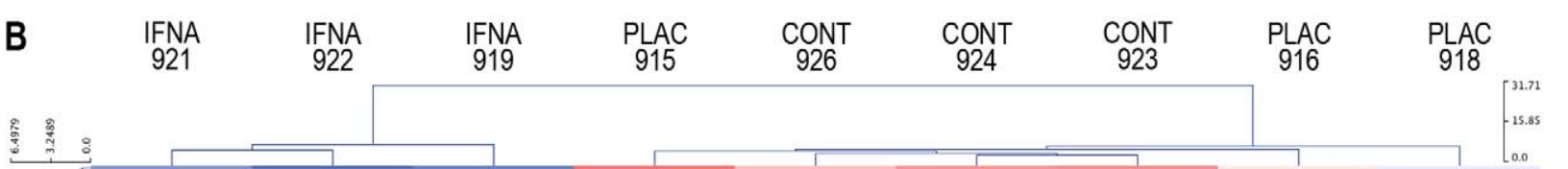



FIG. 1. Results of IFNA2 treatment and comparison to gene expression on D15 and D18 of pregnancy. A) Venn diagram of Limma results of the IFNA2 administration experiment. The overlap of the differentially expressed probe sets for the calculated contrasts is shown. Significant thresholds were $5 \%$ for FDR and 1.5 for fold-change. CONT vs. PLAC, PBS versus placebo; IFNA vs. CONT, human IFNA2 versus control (PBS); IFNA vs. PLAC, IFNA2 vs. placebo (extrudates without IFNA2). B) Cluster analysis of the differentially expressed probe sets resulting from the IFNA2 administration experiment. Normalized expression values (after vsn normalization) were divided by the mean over all samples (mean-centered values). Numbers indicate internal ID of individual heifers. CONT, treatment with PBS; IFNA, treatment with human IFNA2; PLAC: treatment with extrudates without IFNA2. C) Cluster analysis of the genes differentially expressed after treatment with human IFNA2 and/or on D15 of pregnancy. $\log _{2}$-fold changes are shown. Significant thresholds were $5 \%$ for 
TABLE 4. Comparison of effects of human IFNA2 and Days 15 and 18 of pregnancy on endometrial gene expression for typical IFN-stimulated genes (fold change $>5$ for IFNA vs. PLAC).

\begin{tabular}{|c|c|c|c|c|c|c|}
\hline \multirow[b]{2}{*}{ Entrez Gene ID } & \multirow[b]{2}{*}{ Gene symbol } & \multirow[b]{2}{*}{ Gene description } & \multicolumn{4}{|c|}{ Fold change* } \\
\hline & & & IFNA vs. PLAC & IFNA vs. CONT & $15 P$ vs. C & $18 \mathrm{P}$ vs. C \\
\hline 280873 & MX2 & Myxovirus (influenza virus) resistance 2 (mouse) & 42.6 & 46.4 & 40.0 & 47.6 \\
\hline 618737 & BST2 & Bone marrow stromal cell antigen 2 & 20.4 & 20.4 & 23.2 & 25.9 \\
\hline 506415 & RSAD2 & Radical S-adenosyl methionine domain containing 2 & 18.6 & 18.1 & 28.7 & 30.9 \\
\hline 100139670 & IFIT1 & Interferon-induced protein with tetratricopeptide repeats 1 & 17.2 & 16.7 & 27.6 & 28.9 \\
\hline 508347 & LOC508347 & Interferon-induced protein 44-like & 15.3 & 13.3 & 14.2 & 17.2 \\
\hline 521795 & SLFN11 & Schlafen family member 11 & 12.6 & 12.5 & 7.7 & 12.1 \\
\hline 511001 & CLEC4F & C-type lectin domain family 4 , member $\mathrm{F}$ & 12.2 & 12.0 & 7.6 & 14.0 \\
\hline 514205 & SAMD9 & Sterile alpha motif domain containing 9 & 11.1 & 9.9 & 14.4 & 16.1 \\
\hline 515202 & USP18 & Ubiquitin specific peptidase 18 & 10.8 & 9.2 & 12.6 & 12.1 \\
\hline 539759 & SIGLEC1 & Sialic acid binding Ig-like lectin 1, sialoadhesin & 9.6 & 6.7 & 4.8 & 11.3 \\
\hline 654488 & OAS1 & 2',5'-Oligoadenylate synthetase $1,40 / 46 \mathrm{kDa}$ & 9.4 & 9.1 & 12.7 & 9.4 \\
\hline 280872 & MX1 & Myxovirus (influenza virus) resistance 1 & 8.2 & 8.6 & 12.5 & 6.8 \\
\hline 509283 & RNF213 & Ring finger protein 213 & 6.9 & 6.8 & 7.6 & 7.1 \\
\hline 509740 & XAF1 & XIAP associated factor 1 & 6.9 & 6.5 & 6.4 & 8.1 \\
\hline 506759 & IFI16 & Interferon, gamma-inducible protein 16 & 6.7 & 6.0 & 5.6 & 6.9 \\
\hline 507549 & TIMD4 & T-cell immunoglobulin and mucin domain containing 4 & 6.6 & 6.6 & 3.1 & 7.6 \\
\hline 614555 & EPSTI1 & Epithelial stromal interaction 1 (breast) & 6.4 & 5.6 & 6.8 & 10.8 \\
\hline 767910 & PLAC8 & Placenta-specific 8 & 6.0 & 4.1 & 5.1 & 7.3 \\
\hline 527520 & HERC6 & Hect domain and RLD 6 & 6.0 & 6.1 & 3.2 & 6.1 \\
\hline 535490 & IFIH1 & Interferon induced with helicase $\mathrm{C}$ domain 1 & 5.6 & 5.1 & 5.4 & 6.2 \\
\hline 100138545 & PML & Promyelocytic leukemia & 5.5 & 5.2 & 3.9 & 5.8 \\
\hline 508333 & ZBP1 & Z-DNA binding protein 1 & 5.4 & 5.4 & 7.9 & 9.9 \\
\hline 617420 & ISG 12(B) & TLH29 protein precursor-like & 5.4 & 5.2 & 1.5 & 2.7 \\
\hline 514978 & LOC514978 & Lipopolysaccharide-binding protein-like & 5.4 & 5.6 & 2.7 & 13.5 \\
\hline 540789 & PARP14 & Poly (ADP-ribose) polymerase family, member 14 & 5.1 & 5.2 & 5.8 & 6.6 \\
\hline 508378 & $\angle G P 2$ & RNA helicase LGP2 & 5.1 & 5.1 & 5.9 & 5.4 \\
\hline
\end{tabular}

* Adjusted $P$ values for all listed contrasts $<0.05$.

Figure 1B. Expression patterns of the individual samples within the same treatment group were very similar. The sample tree showed no clear separation of PLAC and CONT, corresponding to the results of the statistical analysis. Slight differences in expression patterns between PLAC and CONT were observed, particularly for the probes with lower levels in the IFNA group. Based on these results, the data from the contrast IFNA versus PLAC were used for the comparison with the results from the analysis during early pregnancy. Annotation of the differential probe sets for the contrast IFNA versus PLAC revealed 173 genes with higher levels and 12 genes with lower levels in IFNA samples (Supplemental Table S3).

\section{Comparison of Effects of IFNA2 Treatment to Gene Expression Changes at D15 and D18 of Pregnancy}

For the DEGs obtained at D15 of pregnancy and from IFNA versus PLAC, a cluster analysis was performed based on the $\log _{2}$ fold-changes for IFNA versus PLAC, IFNA versus CONT, and D15 and D18 of pregnancy versus cyclic controls (Fig. 1C). Almost all genes with higher expression levels (Fig.
1C, red) in IFNA versus PLAC also had higher levels in $15 \mathrm{P}$ and 18P samples compared to nonpregnant cyclic samples. Table 4 shows a comparison of fold-changes of typical ISGs. Fold-changes were very similar between IFNA and PLAC and at D15 and D18 of pregnancy (pregnant/cyclic). In contrast, a number of genes showed expression differences in early pregnancy (15P vs. $15 \mathrm{C}$ and/or $18 \mathrm{P}$ vs. 18C) but not after IFNA2 treatment.

Table 5 shows results of the analysis of selected genes by qPCR. Again, similar expression differences were found after IFNA2 treatment and during early pregnancy for typical immune-stimulated genes (upper part of Table 5). Furthermore, differences in the response to IFNA2 treatment compared to D15 and/or D18 of pregnancy were confirmed for genes upregulated after IFNA2 treatment but not or to a lesser extent on D15 and D18, respectively (middle part of Table 5), and for genes upregulated on D15 and/or D18 of pregnancy but not after IFNA2 treatment (bottom part of Table 5).

The DEGs of IFNA versus PLAC and of $15 \mathrm{P}$ versus $15 \mathrm{C}$ (Supplemental Table S3) were then filtered to find genes differentially expressed after IFNA2 treatment but not on D15 of pregnancy and genes differentially expressed at D15 of

FDR and 1.5 for fold-change. 15P vs. 15C, D15 pregnant versus cyclic; 18P vs. 18C, D18 pregnant versus cyclic. Cluster diagrams were produced using Multi Experiment Viewer [89]. In B and C, red indicates values higher than the mean of all samples, and blue indicates values lower than the mean. 
TABLE 5. Validation of expression of selected genes by quantitative real-time RT-PCR (qPCR).

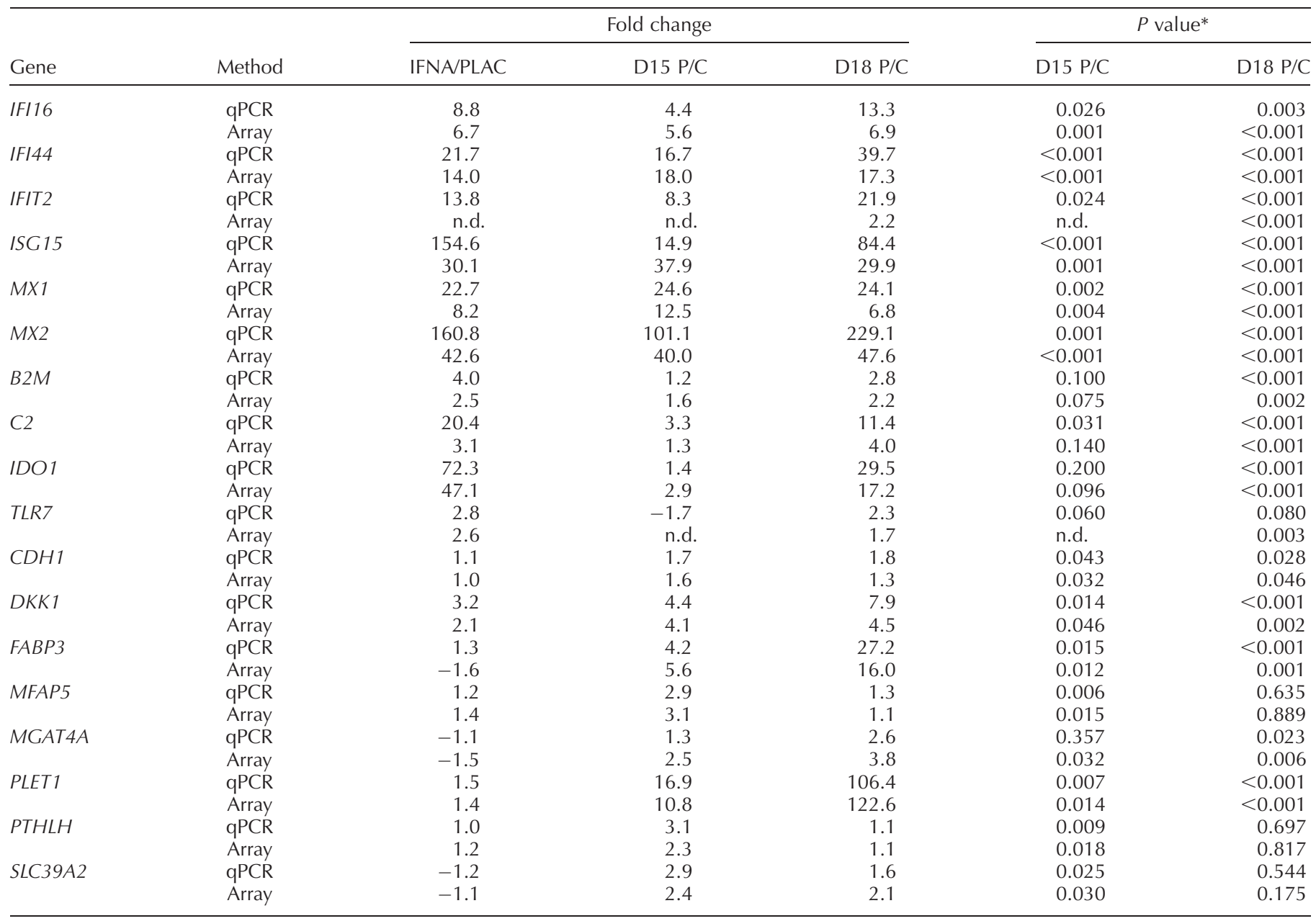

* n.d., not detectable.

pregnancy but not after IFNA2 treatment. Genes effected by IFNA2 but not by pregnancy could indicate differences in the endometrial response to IFNA2 and IFNT and/or modulation of IFN response by additional conceptus-derived factors. Genes differentially expressed in pregnant endometrium but not after IFNA2 treatment could indicate specific effects of IFNT and/or effects of additional embryonic factors.

The DAVID functional annotation clustering of the genes that are differentially expressed for IFNA versus PLAC but not for $15 \mathrm{P}$ versus $15 \mathrm{C}$ (heatmap of expression differences shown in Fig. 2A) revealed quantitatively enriched functional categories mostly related to immune response terms, such as regulation of immune system process, innate immune response, positive regulation of cytokine production, and regulation of $\mathrm{T}$ cell activation (Supplemental Table S7). Furthermore, cocitation analysis of biological keywords (CoPub) found significantly enriched keywords, such as inflammation; phagocytosis; antigen presentation; cell death, apoptosis; cytokine secretion, cytokine production, cytokine biosynthesis; T-cell and B-cell activation, proliferation, and differentiation; and macrophage activation (Supplemental Table S8). Correspondingly, the Kyoto Encyclopedia of Genes and Genomes pathways, which were hit with at least three genes, were also all immune-related: systemic lupus erythematosus, Staphylococcus aureus infection, cytokine-cytokine receptor interaction, complement and coagulation cascades, phagosome, osteoclast differentiation, and chemokine signaling pathway (Supplemental Table S9).
A heatmap of expression differences for genes differentially expressed for $15 \mathrm{P}$ versus $15 \mathrm{C}$ but not or to a lesser extent after IFNA2 treatment is shown in Figure 2B. The DAVID analysis of these genes revealed only two significantly $(P<0.05)$ enriched annotation clusters, one related to transport and one containing genes coding for transmembrane proteins (Supplemental Table S10). CoPub analysis identified no significantly enriched keywords associated with these genes $(P>0.130)$. When setting no $P$-value cut-off, many different biological keywords were obtained, such as transport, tumor-related keywords, homeostasis, metabolism, angiogenesis, growth, cell differentiation, and apoptosis (Supplemental Table S11). Kyoto Encyclopedia of Genes and Genomes pathways that were hit with at least three genes were metabolic pathways, cytokinecytokine receptor interaction, and $N$-glycan biosynthesis (Supplemental Table S12).

Localization of mRNA Expression for Selected Genes by In Situ Hybridization

Four genes-jumonji $\mathrm{C}$ domain containing histone demethylase 1 homolog $\mathrm{D}(J H D M 1 D)$, indoleamine 2,3-dioxygenase 1 (IDOI), fatty acid-binding protein 3, muscle and heart (mammary-derived growth inhibitor) (FABP3), and dickkopf homolog $1(D K K 1)$-were selected for in situ localization of mRNA expression on D13, D16, and D19 of pregnancy and corresponding days of the estrous cycle (Fig. 3). These genes 
were chosen due to their differences in gene expression changes during pregnancy and in response to treatment with human IFNA2 and based on their known or projected functions. JHDMID mRNA was mainly detected in the luminal and glandular epithelium during pregnancy, but it was also detected to a lesser extent during the estrous cycle. IDOI mRNA was observed in immune cells around blood vessels and in myometrium. Expression of FABP3 mRNA was detected in LE and superficial glandular epithelia. Interestingly, $F A B P 3$ decreased from D13 to D19 of the estrous cycle but not in pregnant heifers. $D K K 1$ mRNA was predominantly expressed in stromal cells at D16 and D19 of pregnancy.

\section{DISCUSSION}

The present study was conducted to analyze endometrial responses to the presence of a conceptus at the level of gene expression during the preimplantation phase, with particular emphasis on specific effects of IFNT and/or additional conceptus-derived modulatory factors in comparison to a typical type I IFN, such as IFNA. In addition to their wellknown function in innate immunity via their pleiotropic effects on somatic cells, type I IFNs also play a role in adaptive immune responses, particularly in regulation of $\mathrm{CD}^{+}$and $\mathrm{CD}^{+} \mathrm{T}$ cells [54]. During pregnancy, activation of the specific immune system in the uterus is not desired and has to be modulated to avoid harming the embryo/conceptus. This could be achieved by specific effects of IFNT compared to IFNA2 or by modulatory factors secreted by the conceptus. To investigate differences in the effects of a typical type I IFN and the presence of a conceptus with its secreted factors (mainly IFNT) on the bovine endometrium, gene expression studies of endometrial tissue samples were performed during early pregnancy and after administration of IFNA2, and the results were compared.

Rod-shaped lipid twin-screw extrudates containing human IFNA2 were used to achieve uterine IFNA2 release in a sustained manner over the time of administration [34] to mimic the secretion of IFNT from trophoblast cells of the conceptus during the window of maternal recognition of pregnancy. The proposed antiviral activity released over the 2 days was based on amounts used in previous studies with sheep [19, 38, 39], and extrudates were adjusted accordingly in the in vitro release experiments. To prove release in vivo, antiviral activity was measured in uterine flushings. Antiviral activity was at least one order of magnitude lower compared to the release of extrudates in vitro. This can be explained by limited diffusion in vivo in the uterine lumen, IFNT bound by the endometrium, and IFNT diffusing into the uterine glands; furthermore, IFNT has been shown to be released from the uterus via the uterine vein [55]. Uterine flushings from D12, D15, and D18 of pregnancy were also analyzed for antiviral activity by Groebner et al. [53]. On D12, no antiviral activity was detectable, which is in line with the results of Short et al. [56]. For the D15 pregnant heifers used in the present microarray study, no uterine flushings were available. Considering the D15 pregnant heifers with similar conceptus sizes studied by Groebner et al. [53], antiviral activity was approximately 3000 IU/flush. For the D18 pregnant heifers, mean antiviral activity was $180000 \mathrm{IU} / \mathrm{flush}$. The obtained antiviral activities appear to be lower than reported earlier, because Short et al. [56] found $10^{5} \mathrm{IU} /$ flush on D15 and $10^{7}$ IU/flush on D17 and Loureiro et al. [57] found up to $6 \times 10^{6}$ IU/flush on D15. Altogether, the observed antiviral activity in uterine flushings after the 2 days of IFNA2 administration were in a physiological range comparable to antiviral activity in the uterine lumen during early pregnancy due to production of IFNT by the elongating conceptus.

\section{Analysis of D12, D15, and D18 of Pregnancy}

The microarray analysis of endometrial tissue samples collected during the preimplantation phase did not reveal differential gene expression on D12 of pregnancy, which is in line with recently published data [28] showing no differences on D13 and the finding that no antiviral activity was detectable in uterine flushings from D12 of pregnancy [53]. Although these findings reveal no detectable response in the whole endometrial tissue, a local response in the LE near the D12 conceptus cannot be excluded. Because a number of microarray studies of bovine endometrium during early pregnancy have been published, the present results obtained for D15 and D18 of pregnancy were compared to studies conducted on D16 [28], D17 [30], D18 (genes from Klein et al. [25] and from the present study), and D20 [29] of pregnancy. Overall, a substantial overlap was found for the D15 and D18 of pregnancy upregulated genes with the other studies, although different microarray platforms were used and differences in the data analysis existed. The lowest overlap was observed with the genes upregulated on D20 of pregnancy, a time point after initiation of implantation. However, a different microarray was used for the study by Mansouri-Attia et al. [29], and only the top 100 DEGs were available in the supplemental data, which could be used for GSEA. The highest overlap was obtained for the D15 upregulated genes with the D18 upregulated genes found in the present study, indicating the early response to IFNT on D15 and a full response on D18. In contrast, a much lower overlap was found for the downregulated genes, particularly in the GSEA for D15. Considering that the treatment with human IFNA2 resulted predominantly in stimulation of gene expression, IFNT probably results mainly in upregulation of gene expression, and downregulation could be an effect of the interaction with $\mathrm{P} 4$ action on the endometrium, which differs with cycle stage. Because after D16 the serum P4 concentrations start to decrease, the effects of pregnancy and different $\mathrm{P} 4$ concentrations in the pregnant and control groups could result in a mixture of pregnancy and hormone-level effects. To reduce cycle stage effects, heifers with high P4 concentrations were selected for the D18 control group in the present study. Different biological models (heifers or lactating cows) and different $\mathrm{P} 4$ concentrations in the cyclic control groups (not stated in the other studies) could be a reason for the lower overlap found for the downregulated genes. The overlap of the downregulated genes was also analyzed between the other studies (D16, D17, and D20) and found to be very low.

The characterization of the DEGs using DAVID functional annotation clustering of upregulated genes revealed for both D15 and D18 of pregnancy mainly overrepresented functional categories related to the response to IFNT. The comparison of the gene contents of these categories showed some distinct differences, indicating the existence of early and late IFN response genes, as suggested previously by Forde et al. [28]. For example, genes of the suppressor of cytokine signaling (SOCS) family members $1,3,4$, and 6 , which have been described as negative regulators if IFNT signaling in ovine endometrium [58], were found on D18. Likewise, genes for the cathepsin family members $\mathrm{C}, \mathrm{H}, \mathrm{L} 1, \mathrm{~S}$, and Z were identified as upregulated only on D18 of pregnancy. In ovine endometrium, CTSH, CTSK, CTSL, CTSS, and CTSZ have been described as ISGs [59]. DAVID analysis of the downregulated genes on D18 of pregnancy (higher levels in cyclic controls) revealed a 
BAUERSACHS ET AL.



$\begin{array}{ll}15 P & 18 \mathrm{P} \\ \text { vs. } & \text { vs. }\end{array}$ 15C 18C
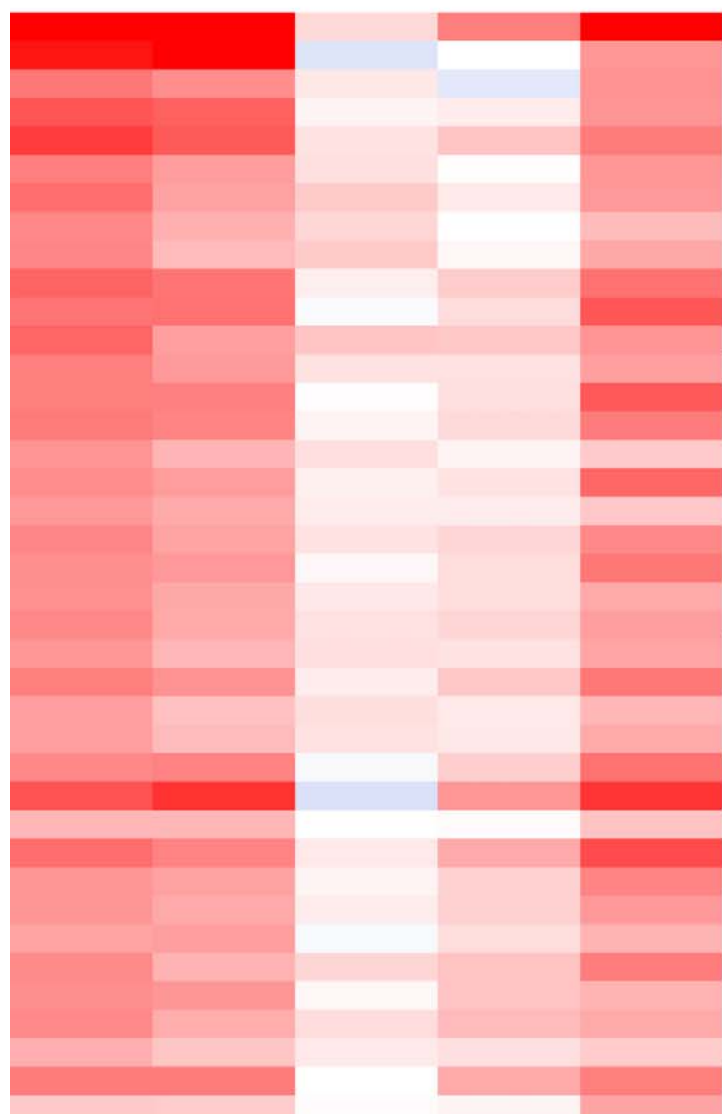

NUPR1

IGHM

HIST1H2BD

HIST4H4

FCGR3A

TMEM156

TLR7

EVI2B

$C 1 Q B$

C2

ARHGAP15

C1QA

OLR1

1QC

CASP1

SIRPA

PDCD1LG2

FCGR1A

CCR5

AlF1

CA4

IL3RA

CSF1R

MPEG1

PMAIP1

CYP2J2-like

U2AF1L 4

CASP 4

HERV-V1

$B O L A-D M B$

HSH2D

TMEM106A

BCL2L 15

LOC781304

PHF15

CCRL1

HIST $3 \mathrm{H} 2 \mathrm{~A}$

FAM13A

GIMAP8

CYP2J2

GIMAP5

CLEC6A

GIMAP6

FILIP1

TAF4B

PIH1D1

ADCY 7

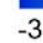

0

3
A

B

$\begin{array}{ccccc}\text { IFNA } & \text { IFNA } & \text { CONT } & 15 P & 18 P \\ \text { VS. } & \text { VS. } & \text { VS. } & \text { VS. } & \text { VS. } \\ \text { PLAC } & \text { CONT } & \text { PLAC } & 15 C & 18 C\end{array}$

HOXB5

HOXB8

HOXB4

NFATC3

TDGF1

GLYAT

CCNB1

CABYR

ALG13

KIAA1549

ILIR2

PLA2G16

TRAK2

SOAT1

SLC40A1

ALG14

RAD21L1

FAM167A

S100A2

MTUS1

MYL3

GSTM1

TBC1D7

PRSS23

KLHL13

HSD17B13

HKDC1

$\mathrm{CDH} 17$

$B O C$

PDE6D

MFAP5

SLC25A33

ECE1

PSAT1

TACR3

PTHLH

NEDD4L

TIPARP

PLEKHA5

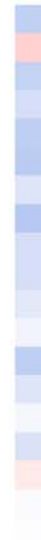

FABP3

PLET1

MGAT4A

TMEM56

SLC25A5

CKMT1

CLDN4

$M A R C H 3$

NUP93

ATF3

PLS1

HIGD1A

$R A B 3 B$

LY6G6C

SLC39A2

POLK

CRYM

SLC12A2

NCDN

SCIN

SLC7A3

TINAGL1

PQLC3

SLC2A1

SERINC2

TNFRSF12A

MPZL 1

TNFSF10

ABLIM3

GDA

DKK1

CCDC6

SMN1

CYCS

MS4A8B

SYNGR1 
number of functional categories related to ECM and protein secretion, in line with previous results from a study of bovine endometrium during the estrous cycle [60]. Among the most significantly enriched functional groups were members of the homeobox family B (B2, B4-B8). HOXB genes have been described in the context of hematopoietic development and differentiation [61], and so far, regulation of these genes has not been described in the endometrium.

\section{Comparison of Gene Expression During Early Pregnancy and after IFNA2 Treatment}

Due to the massive induction of ISGs on D15 and D18 of pregnancy, other, more specific gene expression changes may be covered and so remain unidentified. To mask the typical IFN-induced genes, the data from D15 and D18 of pregnancy were compared to the effects of intrauterine application of human IFNA2. Administration of IFNA2 extrudates from D14 to D16 of the estrous cycle resulted in a specific response at the level of gene expression in the endometrium, because no significant differences were found between PLAC and CONT. The number of DEGs was lower compared to D15 and D16 of pregnancy [28], but more upregulated than downregulated genes were observed, similar to the results obtained on D15 of pregnancy. Comparison of fold-upregulation of typical ISGs showed very similar effects after IFNA2 treatment and at D15 and D18 of pregnancy, indicating that the administered dose of human IFNA2 was in a range to elicit a physiological response of the endometrium. Besides these similar responses, distinct differences were observed-namely, genes with significant expression differences after IFNA2 administration but not at D15 of pregnancy, and vice versa. These genes were analyzed with different bioinformatics tools to characterize their functions.

\section{Genes Showing Stronger Upregulation after IFNA2 Administration Compared to D15 and D18 of Pregnancy}

Most of the genes that showed stronger upregulation in response to IFNA2 compared to early pregnancy are known to be involved in different immune functions, indicating an attenuated response of the maternal immune system during early pregnancy. For example, genes coding for the three subcomponents of complement component $1 \mathrm{q}$ - the initiator of the classical complement pathway, other complement genes, and genes coding for factors interacting with complement proteins-were induced by IFNA2 but not on D15 of pregnancy. Furthermore, DAVID and CoPub analyses revealed that many of the genes induced by IFNA2 but not or to a lesser extent during pregnancy are related to the regulation of $\mathrm{T}$ cells and dendritic cells. For example, adenylate cyclase 7 (ADCY7) has been shown to be involved in regulation of antibody responses toward both $\mathrm{T}$ cell-independent and $\mathrm{T}$ cell-dependent antigens, regulation of memory $\mathrm{T}$ cells, and regulatory $\mathrm{T}$ cells $[62,63]$. The GTPase IMAP (immunity associated protein) family members 5, 6, and 8 (GIMAP5, GIMAP6, and GIMAP8) were shown to regulate the survival of $\mathrm{T}$ cells during development, selection, and T-cell homeostasis and the development of natural killer and natural killer $\mathrm{T}$ cells [64, 65]. A distinct difference in gene expression was found for IDO1. In mice, expression of Idol by trophoblast cells and endometrial macrophages has been shown, leading to suppression of T-cell activity, preventing rejection of the allogeneic concepti [66]. In bovine endometrium, mRNA expression in cells located around blood vessels also suggests expression in immune cells. In a recent study, a strong increase in IDOI expression was observed in cultured bovine endometrial stromal and glandular epithelial cells after treatment with IFNT [67]. The lower increase in IDOI mRNA observed on D15 and D18 of pregnancy compared to the IFNA2 treatment could be due to fine-tuned regulation of the maternal immune system during early pregnancy. In addition to genes involved in regulation of $\mathrm{T}$ cells, CoPub analysis revealed genes described in the context of macrophage and B-cell activation for the genes more induced by IFNA2 treatment compared to pregnancy, such as allograft inflammatory factor 1 (AIF1), colony-stimulating factor 1 receptor $(C S F 1 R)$, and $T L R 7$. Altogether, the immune-related functions of the genes showing attenuated regulation in pregnant endometrium compared to IFNA2 treatment indicate specific effects of IFNT and/or effects of modulatory conceptus-derived factors, which are needed to prevent improper reactions of the maternal immune system.

\section{Genes Not Regulated after IFNA2 Administration but on D15 and/or D18 of Pregnancy}

Both DAVID and CoPub analyses of the genes found as differentially expressed only during pregnancy showed that these genes were very diverse in terms of biological functions. Except for a DAVID functional annotation cluster related to transport, no specific quantitatively enriched processes or functions were found. The category transport contained several members of the solute carrier gene family, including SLC2AI (glucose transporter), $S L C 7 A 3$ (cationic amino acid transporter), SLC12A2 (sodium, potassium, and chloride transporter), SLC25A5 (mitochondrial carrier, adenine nucleotide translocator), SLC25A33 (mitochondrial carrier), SLC39A2 (zinc transporter), and SLC4OAl (iron transmembrane transporter). The two mitochondrial transporters, SLC25A5 and SLC25A33, have a role in cellular energy metabolism [68] and mitochondrial maintenance [69]. For the expression of the glucose transporter gene $S L C 2 A 1$, regulation by conceptus prostaglandins has been shown recently in the ovine uterus [70], indicating that additional conceptus-derived factors influence the endometrial gene expression. This idea is further supported by a study of prostaglandins in the lumen of the bovine uterus at D12, D15, and D18 of the estrous cycle and of pregnancy showing increased levels of prostaglandins at D15 and D18 of pregnancy, from which a considerable part is most probably of embryonic origin [47]. Also, other studies in sheep indicate the role of additional conceptus-derived signaling

FIG. 2. Expression differences of selected genes after treatment with human IFNA2 and on D15 and D18 of pregnancy. A) Genes with significant differences after treatment with human IFNA2 but not on D15 of pregnancy. Genes downregulated after IFNA2 treatment are shown at the top, genes upregulated after IFNA2 treatment but not on D15 of pregnancy in the middle, and genes upregulated after IFNA2 treatment but not on D15 and D18 of pregnancy at the bottom. B) Genes with significant differences on D15 of pregnancy but not after treatment with human IFNA2. Genes downregulated on D15 of pregnancy are shown at the top, genes upregulated only on D15 of pregnancy in the middle, and genes upregulated on D15 and D18 of pregnancy but not after IFNA2 treatment at the bottom. CONT vs. PLAC, PBS control versus placebo; IFNA vs. CONT: IFNA2 versus Control (PBS); IFNA vs. PLAC, human IFNA2 versus placebo (extrudates without IFNA2); 15P vs. 15C, D15 pregnant versus cyclic; 18P vs. 18C, D18 pregnant versus cyclic. Heatmaps were produced using Multi Experiment Viewer [89] and show $\log _{2}$-fold changes. 


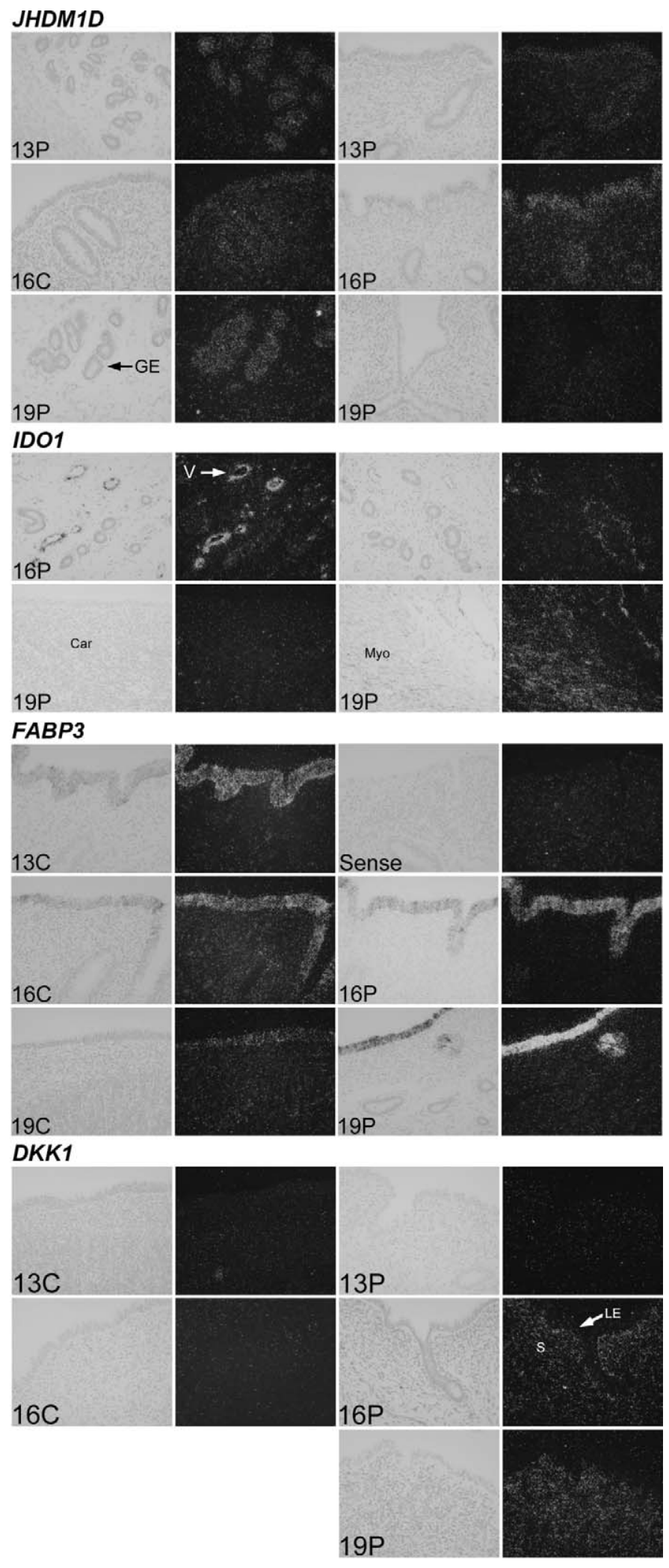

FIG. 3. In situ localization of $/ H D M 1 D, I D O 1, F A B P 3$, and DKK1 mRNA expression in the bovine uterus on D13, D16, and D19 of pregnancy. Cross-sections of the uterine wall from pregnant $(P)$ heifers were hybridized with radiolabeled antisense or sense bovine IHDM1D, IDO1, FABP3, and DKK1 CRNAs and are presented under bright-field and dark-field illumination after counterstaining with hematoxylin. Car, caruncle; GE, glandular epithelium; Myo, myometrium; S, stroma. All photomicrographs are displayed at the same width of field $(450 \mu \mathrm{m})$. molecules in modulation of endometrial gene expression [71], such as prostaglandin produced by the preimplantation ovine conceptus [72]. The increased SLC7A3 expression agrees with the results of a recent study in which higher levels of cationic and other (particularly branched chained) amino acids, were found in uterine flushings from pregnant heifers [73].

The genes showing the strongest upregulation at D15 and D18 of pregnancy but no significant change after IFNA2 treatment were $F A B P 3$ and placenta-expressed transcript 1 protein (PLET1). FABP3 functions in modulation of cell growth and proliferation [74]. In situ hybridization showed specific expression in the LE, suggesting a regulatory role in these cells. Little is known about PLET1, but based on a study by Depreter et al. [75], this gene could also have a role in the development of epithelial cells. For dickkopf homolog 1 (DKK1), coding for an inhibitor of WNT signaling, mRNA expression was found in stromal cells on D16 and D19 of pregnancy. This finding is in line with those studies in human endometrium, in which induction of $D K K 1$ expression by $\mathrm{P} 4$ [76] and specific expression during the window of implantation [77] have been shown.

In addition to the genes SLC39A2 and SLC4OA1 coding for various transporters (see above), a number of genes with very different functions showed elevated expression levels compared to nonpregnant cyclic controls only on D15 of pregnancy and not on D18 or after IFNA2 treatment. These genes could have specific functions in supporting conceptus growth during this phase and/or possibly in the context of maternal recognition of pregnancy. Of these genes, microfibrillar associated protein 5 (MFAP5) has been shown to promote angiogenic cell spouting in vitro by antagonizing Notch signaling pathways in endothelial cells [78], suggesting a role of MFAP5 in endometrial vascular remodeling. A second gene, microtubule-associated tumor suppressor 1 (MTUS1, alias $A T I P)$, was also described in the context of vascular remodeling [79]. Two genes, sterol $O$-acyltransferase 1 (SOAT1) and hydroxysteroid (17-beta) dehydrogenase 13 (HSD17B13), are involved in steroidogenesis [80, 81]. For parathyroid hormone-like hormone $(P T H L H)$, a role in early pregnancy in the rat has been shown by antagonization of PTHLH action leading to fetoplacental growth restriction [82]. Trafficking protein, kinesin-binding 2 (TRAK2, alias GRIF1) is a further potentially interesting gene, because a regulatory role in epidermal growth factor receptor (EGFR) degradation has been shown [83] and EGFR is involved in oxytocin-induced PGF2 $\alpha$ production [84].

Furthermore, a number of genes coding for transcription factors were found with lower expression levels in pregnant endometrium, including three genes of the HOXB transcription factor family. Ectopic expression of $H O X B 8$ in hematopoietic progenitor cells has been shown to negatively regulate granulocyte development in favor of macrophage development [85]. HOXB4 has been involved in differentiation of hematopoietic stem cells [86]. In addition, HOXB factors were described as mediators of the steroid hormones during endometrial cell development [87]. The gene nuclear factor of activated $\mathrm{T}$ cells, cytoplasmic, calcineurin-dependent 3 (NFATC 3) was also downregulated in pregnant endometrium and has been described in the context of development and differentiation of multiple cell types, including immune cells [88]. In the context of the IFNA2-induced genes that were involved in differentiation of immune cells, the lower levels of these transcription factors in pregnant versus cyclic endometrium could be a mechanism to prevent unwanted effects of IFNT. 
In summary, the present study showed that in cattle, endometrial responses on the level of gene expression to the presence of a conceptus are present as early as D15 of pregnancy and that most of these genes are also differentially expressed on D18 of pregnancy. The comparison of gene expression changes in response to pregnancy with changes in response to intrauterine application of human IFNA2 as a classical type I IFN was used as an attempt to dissect the response of the bovine endometrium to a classical type I IFN and the presence of a conceptus that secretes the pregnancyspecific IFNT and additional signaling molecules, such as PGs. Though we found a broad overlap of the responses in the pregnant and IFNA2 treatment groups to the corresponding controls, distinct differences suggested a fine-tuned modulation of pregnancy signaling by the conceptus. This could be due to slightly different signaling via the IFN receptor by IFNT and/or due to conceptus-derived factors other than IFNT. Furthermore, the slow-release device (extrudate) developed in the present study is an interesting tool for releasing defined amounts of IFNs or other molecules in a physiological manner, which could also allow one to specifically address maternal factors, such as genetic background, parity, or metabolic disturbances, in the early embryo-maternal cross-talk.

\section{ACKNOWLEDGMENT}

We thank Karin Groß, Andrea Klanner, and Angela Sachsenhauser for excellent technical assistance.

\section{REFERENCES}

1. Roberts RM, Chen Y, Ezashi T, Walker AM. Interferons and the maternalconceptus dialog in mammals. Semin Cell Dev Biol 2008; 19:170-177.

2. Bazer FW, Wu G, Spencer TE, Johnson GA, Burghardt RC, Bayless K. Novel pathways for implantation and establishment and maintenance of pregnancy in mammals. Mol Hum Reprod 2010; 16:135-152.

3. Johnson GA, Bazer FW, Burghardt RC, Spencer TE, Wu G, Bayless KJ. Conceptus-uterus interactions in pigs: endometrial gene expression in response to estrogens and interferons from conceptuses. Soc Reprod Fertil Suppl 2009; 66:321-332.

4. Bazer FW, Spencer TE, Johnson GA. Interferons and uterine receptivity. Semin Reprod Med 2009; 27:90-102.

5. Cochet M, Vaiman D, Lefevre F. Novel interferon delta genes in mammals: cloning of one gene from the sheep, two genes expressed by the horse conceptus and discovery of related sequences in several taxa by genomic database screening. Gene 2009; 433:88-99.

6. Godkin JD, Bazer FW, Roberts RM. Ovine trophoblast protein 1, an early secreted blastocyst protein, binds specifically to uterine endometrium and affects protein synthesis. Endocrinology 1984; 114:120-130.

7. Hansen PJ, Anthony RV, Bazer FW, Baumbach GA, Roberts RM. In vitro synthesis and secretion of ovine trophoblast protein-1 during the period of maternal recognition of pregnancy. Endocrinology 1985; 117:1424-1430.

8. Helmer SD, Hansen PJ, Anthony RV, Thatcher WW, Bazer FW, Roberts RM. Identification of bovine trophoblast protein-1, a secretory protein immunologically related to ovine trophoblast protein-1. J Reprod Fertil 1987; 79:83-91.

9. Spencer TE, Johnson GA, Bazer FW, Burghardt RC. Fetal-maternal interactions during the establishment of pregnancy in ruminants. Soc Reprod Fertil Suppl 2007; 64:379-396.

10. Murphy SP, Tayade C, Ashkar AA, Hatta K, Zhang J, Croy BA. Interferon gamma in successful pregnancies. Biol Reprod 2009; 80:848-859.

11. Roberts RM. Interferon-tau, a type 1 interferon involved in maternal recognition of pregnancy. Cytokine Growth Factor Rev 2007; 18:403408.

12. Farin CE, Imakawa K, Roberts RM. In situ localization of mRNA for the interferon, ovine trophoblast protein-1, during early embryonic development of the sheep. Mol Endocrinol 1989; 3:1099-1107.

13. Spencer TE, Bazer FW. Ovine interferon tau suppresses transcription of the estrogen receptor and oxytocin receptor genes in the ovine endometrium. Endocrinology 1996; 137:1144-1147.

14. Bazer FW, Burghardt RC, Johnson GA, Spencer TE, Wu G. Interferons and progesterone for establishment and maintenance of pregnancy: interactions among novel cell signaling pathways. Reprod Biol 2008; 8:179-211.

15. Hansen TR, Henkes LK, Ashley RL, Bott RC, Antoniazzi AQ, Han H. Endocrine actions of interferon-tau in ruminants. Soc Reprod Fertil Suppl 2010; 67:325-340.

16. Demmers KJ, Derecka K, Flint A. Trophoblast interferon and pregnancy. Reproduction 2001; 121:41-49.

17. Li J, Roberts RM. Interferon-tau and interferon-alpha interact with the same receptors in bovine endometrium. Use of a readily iodinatable form of recombinant interferon-tau for binding studies. J Biol Chem 1994; 269:13544-13550.

18. Subramaniam PS, Khan SA, Pontzer CH, Johnson HM. Differential recognition of the type I interferon receptor by interferons tau and alpha is responsible for their disparate cytotoxicities. Proc Natl Acad Sci U S A 1995; 92:12270-12274.

19. Green MP, Spate LD, Bixby JA, Ealy AD, Roberts RM. A comparison of the anti-luteolytic activities of recombinant ovine interferon-alpha and -tau in sheep. Biol Reprod 2005; 73:1087-1093.

20. Pontzer CH, Yamamoto JK, Bazer FW, Ott TL, Johnson HM. Potent antifeline immunodeficiency virus and anti-human immunodeficiency virus effect of IFN-tau. J Immunol 1997; 158:4351-4357.

21. Plante C, Hansen PJ, Thatcher WW. Prolongation of luteal lifespan in cows by intrauterine infusion of recombinant bovine alpha-interferon. Endocrinology 1988; 122:2342-2344.

22. Imakawa K, Tamura K, Lee RS, Ji Y, Kogo H, Sakai S, Christenson RK. Temporal expression of type I interferon receptor in the peri-implantation ovine extra-embryonic membranes: demonstration that human IFNalpha can bind to this receptor. Endocr J 2002; 49:195-205.

23. Russell DL, Manalo GG Jr, Findlay JK, Salamonsen LA. Binding sites for interferons on ovine and human endometrial membranes. Reprod Fertil Dev 1993; 5:219-227.

24. Salamonsen LA, Manikhot J, Healy DL, Findlay JK. Ovine trophoblast protein-1 and human interferon alpha reduce prostaglandin synthesis by ovine endometrial cells. Prostaglandins 1989; 38:289-306.

25. Klein C, Bauersachs S, Ulbrich SE, Einspanier R, Meyer HH, Schmidt SE, Reichenbach HD, Vermehren M, Sinowatz F, Blum H, Wolf E. Monozygotic twin model reveals novel embryo-induced transcriptome changes of bovine endometrium in the preattachment period. Biol Reprod 2006; 74:253-264.

26. Bauersachs S, Ulbrich SE, Gross K, Schmidt SE, Meyer HH, Wenigerkind H, Vermehren M, Sinowatz F, Blum H, Wolf E. Embryo-induced transcriptome changes in bovine endometrium reveal species-specific and common molecular markers of uterine receptivity. Reproduction 2006; 132:319-331.

27. Bauersachs S, Mitko K, Ulbrich SE, Blum H, Wolf E. Transcriptome studies of bovine endometrium reveal molecular profiles characteristic for specific stages of estrous cycle and early pregnancy. Exp Clin Endocrinol Diabetes 2008; 116:371-384.

28. Forde N, Carter F, Spencer TE, Bazer FW, Sandra O, Mansouri-Attia N, Okumu LA, McGettigan PA, Mehta JP, McBride R, O’Gaora P, Roche JF, et al. Conceptus-induced changes in the endometrial transcriptome: how soon does the cow know she is pregnant? Biol Reprod 2011; 85:144-156.

29. Mansouri-Attia N, Aubert J, Reinaud P, Giraud-Delville C, Taghouti G, Galio L, Everts RE, Degrelle S, Richard C, Hue I, Yang X, Tian XC, et al. Gene expression profiles of bovine caruncular and intercaruncular endometrium at implantation. Physiol Genomics 2009; 39:14-27.

30. Walker CG, Meier S, Littlejohn MD, Lehnert K, Roche JR, Mitchell MD. Modulation of the maternal immune system by the pre-implantation embryo. BMC Genomics 2010; 11:474.

31. Gray CA, Abbey CA, Beremand PD, Choi Y, Farmer JL, Adelson DL, Thomas TL, Bazer FW, Spencer TE. Identification of endometrial genes regulated by early pregnancy, progesterone, and interferon tau in the ovine uterus. Biol Reprod 2006; 74:383-394.

32. Chen Y, Antoniou E, Liu Z, Hearne LB, Roberts RM. A microarray analysis for genes regulated by interferon-tau in ovine luminal epithelial cells. Reproduction 2007; 134:123-135.

33. Satterfield MC, Song G, Kochan KJ, Riggs PK, Simmons RM, Elsik CG, Adelson DL, Bazer FW, Zhou H, Spencer TE. Discovery of candidate genes and pathways in the endometrium regulating ovine blastocyst growth and conceptus elongation. Physiol Genomics 2009; 39:85-99.

34. Schulze S, Winter G. Lipid extrudates as novel sustained release systems for pharmaceutical proteins. J Control Release 2009; 134:177-185.

35. Wehrend A, Trasch K, Failing K, Bostedt H. [The regional differences of the $\mathrm{pH}$-value in the vagina, cervix, and uterus of cows during interestrus] [In German]. Dtsch Tierarztl Wochenschr 2003; 110:65-68.

36. Mohl S, Winter G. Continuous release of rh-interferon alpha-2a from 
triglyceride implants: storage stability of the dosage forms. Pharm Dev Technol 2006; 11:103-110.

37. Rubinstein S, Familletti PC, Pestka S. Convenient assay for interferons. J Virol 1981; 37:755-758.

38. Chen Y, Green JA, Antoniou E, Ealy AD, Mathialagan N, Walker AM, Avalle MP, Rosenfeld CS, Hearne LB, Roberts RM. Effect of interferontau administration on endometrium of nonpregnant ewes: a comparison with pregnant ewes. Endocrinology 2006; 147:2127-2137.

39. Spencer TE, Ing NH, Ott TL, Mayes JS, Becker WC, Watson GH, Mirando MA, Brazer FW. Intrauterine injection of ovine interferon-tau alters estrogen receptor and oxytocin receptor expression in the endometrium of cyclic ewes. J Mol Endocrinol 1995; 15:203-220.

40. Simmons RM, Erikson DW, Kim J, Burghardt RC, Bazer FW, Johnson GA, Spencer TE. Insulin-like growth factor binding protein-1 in the ruminant uterus: potential endometrial marker and regulator of conceptus elongation. Endocrinology 2009; 150:4295-4305.

41. Bridges GA, Helser LA, Grum DE, Mussard ML, Gasser CL, Day ML. Decreasing the interval between GnRH and PGF2alpha from 7 to 5 days and lengthening proestrus increases timed-AI pregnancy rates in beef cows. Theriogenology 2008; 69:843-851.

42. Irizarry RA, Hobbs B, Collin F, Beazer-Barclay YD, Antonellis KJ, Scherf $\mathrm{U}$, Speed TP. Exploration, normalization, and summaries of high density oligonucleotide array probe level data. Biostatistics 2003; 4:249-264.

43. Smyth GK. Linear models and empirical Bayes methods for assessing differential expression in microarray experiments. Stat Appl Genet Mol Biol 2004; 3: Article 3.

44. Subramanian A, Kuehn H, Gould J, Tamayo P, Mesirov JP. GSEA-P: a desktop application for Gene Set Enrichment Analysis. Bioinformatics 2007; 23:3251-3253.

45. Dennis G Jr, Sherman BT, Hosack DA, Yang J, Gao W, Lane HC, Lempicki RA. DAVID: Database for Annotation, Visualization, and Integrated Discovery. Genome Biol 2003; 4:P3.

46. Frijters R, Heupers B, van Beek P, Bouwhuis M, van Schaik R, de Vlieg J, Polman J, Alkema W. CoPub: a literature-based keyword enrichment tool for microarray data analysis. Nucleic Acids Res 2008; 36:W406-W410.

47. Ulbrich SE, Schulke K, Groebner AE, Reichenbach HD, Angioni C, Geisslinger G, Meyer HH. Quantitative characterization of prostaglandins in the uterus of early pregnant cattle. Reproduction 2009; 138:371-382.

48. Bustin SA, Benes V, Garson JA, Hellemans J, Huggett J, Kubista M, Mueller R, Nolan T, Pfaffl MW, Shipley GL, Vandesompele J, Wittwer CT. The MIQE guidelines: minimum information for publication of quantitative real-time PCR experiments. Clin Chem 2009; 55:611-622.

49. Livak KJ, Schmittgen TD. Analysis of relative gene expression data using real-time quantitative PCR and the 2(-Delta Delta C(T)) Method. Methods 2001; 25:402-408.

50. Spencer TE, Stagg AG, Joyce MM, Jenster G, Wood CG, Bazer FW, Wiley AA, Bartol FF. Discovery and characterization of endometrial epithelial messenger ribonucleic acids using the ovine uterine gland knockout model. Endocrinology 1999; 140:4070-4080.

51. King GJ, Atkinson BA, Robertson HA. Development of the bovine placentome from days 20 to 29 of gestation. J Reprod Fertil 1980; 59:95100 .

52. Wathes DC, Wooding FB. An electron microscopic study of implantation in the cow. Am J Anat 1980; 159:285-306.

53. Groebner AE, Schulke K, Unterseer S, Reichenbach HD, Reichenbach M, Buttner M, Wolf E, Meyer HH, Ulbrich SE. Enhanced proapoptotic gene expression of XAF1, CASP8 and TNFSF10 in the bovine endometrium during early pregnancy is not correlated with augmented apoptosis. Placenta 2010; 31:168-177.

54. Huber JP, Farrar JD. Regulation of effector and memory T-cell functions by type I interferon. Immunology 2011; 132:466-474.

55. Oliveira JF, Henkes LE, Ashley RL, Purcell SH, Smirnova NP, Veeramachaneni DN, Anthony RV, Hansen TR. Expression of interferon (IFN)-stimulated genes in extrauterine tissues during early pregnancy in sheep is the consequence of endocrine IFN-tau release from the uterine vein. Endocrinology 2008; 149:1252-1259.

56. Short EC Jr, Geisert RD, Helmer SD, Zavy MT, Fulton RW. Expression of antiviral activity and induction of $2^{\prime}, 5^{\prime}$-oligoadenylate synthetase by conceptus secretory proteins enriched in bovine trophoblast protein-1. Biol Reprod 1991; 44:261-268.

57. Loureiro B, Block J, Favoreto MG, Carambula S, Pennington KA, Ealy $\mathrm{AD}$, Hansen PJ. Consequences of conceptus exposure to colonystimulating factor 2 on survival, elongation, interferon-tau secretion, and gene expression. Reproduction 2011; 141:617-624.

58. Sandra O, Bataillon I, Roux P, Martal J, Charpigny G, Reinaud P, Bolifraud P, Germain G, Al-Gubory KH. Suppressor of cytokine signalling (SOCS) genes are expressed in the endometrium and regulated by conceptus signals during early pregnancy in the ewe. J Mol Endocrinol 2005; 34:637-644.

59. Song G, Spencer TE, Bazer FW. Cathepsins in the ovine uterus: regulation by pregnancy, progesterone, and interferon tau. Endocrinology 2005; 146:4825-4833.

60. Mitko K, Ulbrich SE, Wenigerkind H, Sinowatz F, Blum H, Wolf E, Bauersachs S. Dynamic changes in messenger RNA profiles of bovine endometrium during the estrous cycle. Reproduction 2008; 135:225-240.

61. Magli MC, Largman C, Lawrence HJ. Effects of HOX homeobox genes in blood cell differentiation. J Cell Physiol 1997; 173:168-177.

62. Bazhin AV, Kahnert S, Kimpfler S, Schadendorf D, Umansky V. Distinct metabolism of cyclic adenosine monophosphate in regulatory and helper CD4+ T cells. Mol Immunol 2010; 47:678-684.

63. Duan B, Davis R, Sadat EL, Collins J, Sternweis PC, Yuan D, Jiang LI. Distinct roles of adenylyl cyclase VII in regulating the immune responses in mice. J Immunol 2010; 185:335-344.

64. Nitta T, Takahama Y. The lymphocyte guard-IANs: regulation of lymphocyte survival by IAN/GIMAP family proteins. Trends Immunol 2007; 28:58-65.

65. Schulteis RD, Chu H, Dai X, Chen Y, Edwards B, Haribhai D, Williams CB, Malarkannan S, Hessner MJ, Glisic-Milosavljevic S, Jana S, Kerschen EJ, et al. Impaired survival of peripheral T cells, disrupted NK/NKT cell development, and liver failure in mice lacking Gimap5. Blood 2008; 112:4905-4914.

66. Munn DH, Zhou M, Attwood JT, Bondarev I, Conway SJ, Marshall B, Brown C, Mellor AL. Prevention of allogeneic fetal rejection by tryptophan catabolism. Science 1998; 281:1191-1193.

67. Groebner AE, Schulke K, Schefold JC, Fusch G, Sinowatz F, Reichenbach $\mathrm{HD}$, Wolf E, Meyer HH, Ulbrich SE. Immunological mechanisms to establish embryo tolerance in early bovine pregnancy. Reprod Fertil Dev 2011; 23:619-632.

68. Chevrollier A, Loiseau D, Reynier P, Stepien G. Adenine nucleotide translocase 2 is a key mitochondrial protein in cancer metabolism. Biochim Biophys Acta 2011; 1807:562-567.

69. Favre C, Zhdanov A, Leahy M, Papkovsky D, O’Connor R. Mitochondrial pyrimidine nucleotide carrier (PNC1) regulates mitochondrial biogenesis and the invasive phenotype of cancer cells. Oncogene 2010; 29:39643976.

70. Dorniak P, Bazer FW, Spencer TE. Prostaglandins regulate conceptus elongation and mediate effects of interferon tau on the ovine uterine endometrium. Biol Reprod 2011; 84:1119-1127.

71. Simmons RM, Satterfield MC, Welsh TH Jr, Bazer FW, Spencer TE. HSD11B1, HSD11B2, PTGS2, and NR3C1 expression in the periimplantation ovine uterus: effects of pregnancy, progesterone, and interferon tau. Biol Reprod 2010; 82:35-43.

72. Charpigny G, Reinaud P, Tamby JP, Creminon C, Guillomot M. Cyclooxygenase-2 unlike cyclooxygenase-1 is highly expressed in ovine embryos during the implantation period. Biol Reprod 1997; 57:10321040.

73. Groebner AE, Rubio-Aliaga I, Schulke K, Reichenbach HD, Daniel H, Wolf E, Meyer HH, Ulbrich SE. Increase of essential amino acids in the bovine uterine lumen during preimplantation development. Reproduction 2011; 141:685-695.

74. Huynh H, Pollak M. Stabilization of mammary-derived growth inhibitor messenger RNA by antiestrogens. Clin Cancer Res 1997; 3:2151-2156.

75. Depreter MG, Blair NF, Gaskell TL, Nowell CS, Davern K, Pagliocca A, Stenhouse FH, Farley AM, Fraser A, Vrana J, Robertson K, Morahan G, et al. Identification of Plet-1 as a specific marker of early thymic epithelial progenitor cells. Proc Natl Acad Sci U S A 2008; 105:961-966.

76. Wang Y, Hanifi-Moghaddam P, Hanekamp EE, Kloosterboer HJ, Franken P, Veldscholte J, van Doorn HC, Ewing PC, Kim JJ, Grootegoed JA, Burger CW, Fodde R, et al. Progesterone inhibition of Wnt/beta-catenin signaling in normal endometrium and endometrial cancer. Clin Cancer Res 2009; 15:5784-5793.

77. Tapia A, Vilos C, Marin JC, Croxatto HB, Devoto L. Bioinformatic detection of E47, E2F1 and SREBP1 transcription factors as potential regulators of genes associated to acquisition of endometrial receptivity. Reprod Biol Endocrinol 2011; 9:14.

78. Albig AR, Becenti DJ, Roy TG, Schiemann WP. Microfibril-associate glycoprotein-2 (MAGP-2) promotes angiogenic cell sprouting by blocking notch signaling in endothelial cells. Microvasc Res 2008; 76:7-14.

79. Rodrigues-Ferreira S, Nahmias C. An ATIPical family of angiotensin II AT2 receptor-interacting proteins. Trends Endocrinol Metab 2010; 21:684-690.

80. Ferraz-de-Souza B, Hudson-Davies RE, Lin L, Parnaik R, Hubank M, Dattani MT, Achermann JC. Sterol $O$-acyltransferase 1 (SOAT1, ACAT) 
is a novel target of steroidogenic factor-1 (SF-1, NR5A1, Ad4BP) in the human adrenal. J Clin Endocrinol Metab 2011; 96:E663-E668.

81. Moe M, Lien S, Bendixen C, Hedegaard J, Hornshoj H, Berget I, Meuwissen TH, Grindflek E. Gene expression profiles in liver of pigs with extreme high and low levels of androstenone. BMC Vet Res 2008; 4:29.

82. Thota CS, Reed LC, Yallampalli C. Effects of parathyroid hormone like hormone (PTHLH) antagonist, PTHLH(7-34), on fetoplacental development and growth during midgestation in rats. Biol Reprod 2005; 73:11911198.

83. Kirk E, Chin LS, Li L. GRIF1 binds Hrs and is a new regulator of endosomal trafficking. J Cell Sci 2006; 119:4689-4701.

84. Krishnaswamy N, Lacroix-Pepin N, Chapdelaine P, Taniguchi H, Kauffenstein G, Chakravarti A, Danyod G, Fortier MA. Epidermal growth factor receptor is an obligatory intermediate for oxytocin-induced cyclooxygenase 2 expression and prostaglandin F2 alpha production in bovine endometrial epithelial cells. Endocrinology 2010; 151:1367-1374.

85. Krishnaraju K, Hoffman B, Liebermann DA. Lineage-specific regulation of hematopoiesis by HOX-B8 (HOX-2.4): inhibition of granulocytic differentiation and potentiation of monocytic differentiation. Blood 1997; 90:1840-1849.

86. Sharma S, Gurudutta GU, Satija NK, Pati S, Afrin F, Gupta P, Verma YK, Singh VK, Tripathi RP. Stem cell c-KIT and HOXB4 genes: critical roles and mechanisms in self-renewal, proliferation, and differentiation. Stem Cells Dev 2006; 15:755-778.

87. Gao J, Mazella J, Tseng L. Hox proteins activate the IGFBP-1 promoter and suppress the function of hPR in human endometrial cells. DNA Cell Biol 2002; 21:819-825.

88. Horsley V, Pavlath GK. NFAT: ubiquitous regulator of cell differentiation and adaptation. J Cell Biol 2002; 156:771-774.

89. Saeed AI, Sharov V, White J, Li J, Liang W, Bhagabati N, Braisted J, Klapa M, Currier T, Thiagarajan M, Sturn A, Snuffin M, et al. TM4: a free, open-source system for microarray data management and analysis. Biotechniques 2003; 34:374-378.

90. Browne EP, Wing B, Coleman D, Shenk T. Altered cellular mRNA levels in human cytomegalovirus-infected fibroblasts: viral block to the accumulation of antiviral mRNAs. J Virol 2001; 75:12319-12330. 